\title{
Assessment and Projection of Climate Change Impacts on Malaria Distribution in Ethiopia: Case of Combolcha and Debark Districts
}

\author{
Abrhame Weldeyohannes Gilgel (Msc) ${ }^{1^{*}}$, Tadesse Terefe $(\mathrm{PhD})^{2}$, Mesfin Asfaw $(\mathrm{PhD})^{3}$ \\ ${ }^{I}$ National Meteorological Agency of Ethiopia \\ ${ }^{2}$ Addis Ababa University, Ethiopia \\ ${ }^{3}$ Adama Science and Technology University, Ethiopia
}

\begin{abstract}
*Corresponding Author: Abrhame Weldeyohannes Gilgel (Msc), National Meteorological Agency of Ethiopia
\end{abstract}

\begin{abstract}
Climate change has a significant impact on the environment, socio-economic as well as on public health, especially on the transmission of malaria disease. Some sources of facts display that while no precisely defined limit exists beyond which malaria will not be found, recently a malaria distribution case has been seen in high land areas of Eastern Africa (e.g. Ethiopian). In this study, we assess and predict the impact of climate change on elevation-dependent malaria distribution temporally over Combolcha and Debark districts which are high lands of Ethiopia where there was no the case in history. The method applied for assessment and projection of climate variability is statistical approach, in general. And for assessment and projection of climate driven malaria distribution, the method used was based on the intersection of the favorable climate parameters: Precipitation, Temperature and Relative Humidity with the suitable threshold values. Thus, gradual malaria expansion to higher altitudes is justified in association to climate change and variability. In the result, we determine that the change and variability in precipitation was more significant ( 0.64 correlation) in controlling malaria transmission than the temperature over relative lower elevation areas (Combolcha). On the reverse, the change and variability in temperature ( 0.53 correlation) takes the first place in controlling malaria transmission over Debark. Moreover, the result indicates that the climate change and variability allowed malaria transmission site potentially tending to elevate to the high lands of Ethiopia like Debark district, recently in 2015 and 2016. In addition, the altitude 2,800 $\mathrm{m}$ above mean sea level was determined to be the demarcation point-level above which the disease malaria could not existed in Debark woreda for the period (1986-2016). Again, this assessment result demonstrated malaria transmission site to reach at 2,800m while the result obtained using MARA13 malaria projection model puts the elevation at 2,500 m, for 2015. Finally, we conclude that due to the present and future climate change malaria occurred on recent-time over new places of Ethiopia, in particular over high lands of Debark district; and in future, there is an indication to malaria persist over 2,800m elevation and incident on beyond this topographical height.
\end{abstract}

Keywords: Climate variability and change; Climate Impact; Malaria Distribution

\section{INTRODUCTION}

The dynamics of Earth's climate system have been affecting human life. Climate along with its variability and change had been observed laying impressive impacts on different socio-economic activities such as: agricultural, power generation, water supply, public health, social and political issues, (IPCC, 2015). An increase in greenhouse gases leads to increased warming of the atmosphere, ocean and the Earth's surface. As a result, climate change become familiar in the past, present and future time, C. McSweeney et al 2006, Z. T. Segel et al 2008 \& USAID 2015. Beside to this, H. F. DAIZ and R. S. BRADLEY, 1997 found evidence for appreciable differences in mean temperature changes with elevation during the last several decades. And, according to I. Rangwala \& J. R. Miller, January 2012 the sensitivity of climate changes to surface elevations, is remarkable just like to the climate changes identified at a horizontal surface with fixed altitudes. Existing literature suggests that global warming or inter-annual/decadal climate variability have a direct influence on the epidemiology of vector-borne diseases. As WMO \& WHO, Sept. 2015 of the Intergovernmental Panel on Climate Change (IPCC), anticipated changes in temperature and rainfall will affect the natural 
habitats of mosquitoes, changing the prevalence of the vector or prolonging transmission seasons or both in some areas, and potentially exposing new regions and populations to malaria and result in negative impact on developmental gains. In the face of climate change, Author's Guide, 2014 malaria ranges are quickly expanding. Parts of Ethiopia that have never been affected by malaria are now seeing their populations infected by this disease due to climate change. In this study we have a plan to assess the impact of climate change on malaria distribution in temporal and spatial bases over North and North-East regions of Amhara, in Ethiopia, where now there is a new case of malaria incidence than before.

While no precisely defined limit exists beyond which malaria will not be found, researches deal with that 2,000 meters was the elevation beyond which malaria was believed unlikely to exist. That limit, however, has been identified at a much lower level for some countries and at much higher levels for others. Such limitations are based on climate suitability that enable how far up mountains and highlands mosquitoes are able to go in particular localities and not on any other. In general, an elevation of 1,500 meters above sea level is used to define the limit above which the likelihood of finding malaria will be rare. This puts up Eastern Africa's various highlands above that limit; but again, the disease has been found in some areas of Ethiopia above 2,000 meters. In line with this, in different occasions, while the meetings made for seasonal forecasting hosted by National Meteorology Agency of Ethiopia, stakeholders put their fundamental feedback regarding to the information provided for health sectors. In their response they said that "The data collected from NMA have been giving a good indicator for occurrence of malaria in different regions of the country. However, recently a malaria distribution case has been seen in high land areas of Ethiopian (such as Combolcha and Debark woredas health center). But, the information gathered from NMA did not reveal this special case of incidence of malaria over those places. This is where the problem comes and gaps are seen in the service of NMA for health sector. Definitely, the gap is due to shortage in frequent studies in assessing of malaria distribution considering the influence of climate change. This leads us to limited understanding of the relationship between climate and the disease as a result we are unable to observe the actual facts over local places. For this reason, our knowledge of climate impact on malaria distribution for higher elevations needs to be updated. Besides, the main and the primary problem is lack of high-resolution data that can represent each specific area with different altitude, even within a single district.

\section{MATERIALS AND MethodS}

\subsection{Description of the Study Area}

This study was carried out in Northern and North-Eastern Ethiopia. Particularly, Combolcha and Debark woredas are found around Eastern and Northern Amhara region, with in the Weyna-Dega and Dega agro-ecological zone, respectively. Combolcha is located $08045^{\prime} 0^{\prime}$ ' N, $38058^{\prime}$ '59' ' E, which is $367 \mathrm{~km}$ at North-Eastern direction from Addis Ababa capital city of Ethiopia; and Debark is located at $822 \mathrm{~km}$ Northern direction, from Addis Ababa, with latitude and longitude of 9.6o N and 37.9o E, respectively. The altitude at the sites is an elevation 1915 and 2850 meters above sea level for Combolcha and Debark respectively.

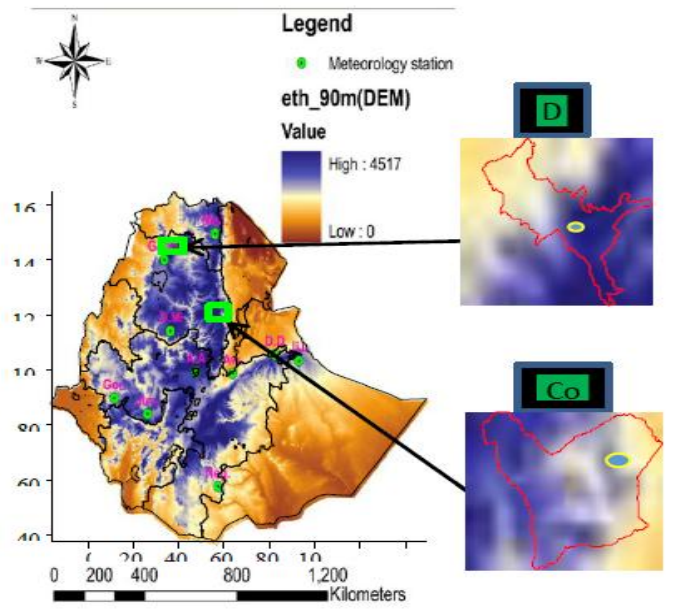

Figure1. Meteorological Station Distribution and Topography Map of the Study Area, the circles represent the study areas \& the corresponding towns in the woredas. 


\subsection{Materials}

\subsubsection{Data}

Data/Materials used for the research work was climatological data collected from NMA, ENACTS and IRI Websites of world data set etc. ENACTS data set is a high-resolution climate data with area coverage of four by four $\mathrm{km}$ for a single grid cell. In Amhara region, there are different classes of meteorological stations, based on quality and quantity of products. Combolcha and Debark Meteorological stations are categorized first and second-class meteorological stations respectively. In this study, monthly total precipitation, monthly mean of daily average of maximum \& minimum temperature and monthly mean relative humidity was used for the period of 1986-2016.

\subsubsection{Data Processing and Analyzing Tools}

One of the Starting points of this study was to assess the Climate characteristics of the study areas and demonstrate climate variabilities over the areas under investigation. For such objective we used Instat+V 3.37 software, Mann-Kendall program software, XLSTAT, excel spreadsheet, and Surfer version8/ GIS for the statistical analysis of both climate characteristics and generating climate-based malaria distribution information.

\subsubsection{Quality Control and Missing Data}

Initially, missing station data was substituted with ENACTS reanalysis data by the nearest latitude and longitude spatial reference location. The other technical method applied for filling missing data is using weighted mean formula as expressed below in equation 1.

$$
X=\sum_{i=1}^{n}(x i * w i) / \sum_{i=1}^{n} w i \quad 1
$$

The other essential data processing unit was data quality control which is determinant for the quality of the research result. And then, in place of low-quality data the above equation [1] is used here again to correct and substitute the data with low quality.

\subsection{Methods and Procedures}

To identify the relationship between climate variability/change and malaria characteristics we applied similar statistical methods with Grover-Kopek et al. 2006. The detail is presented under the next sub sections.

\subsubsection{Assessment and Characterization of Climate of the Study Areas (1986-2016)}

I. Climate Variability: To understand the intensity of climatic variabilities and deviations from the climate mean, coefficient of variation

$$
C V=\frac{\delta}{\mu} * 100 \%
$$

and standardized deviation anomaly written as

$$
(S)^{*}=\frac{(\underline{\eta}-\tilde{\eta})}{S} \quad 3
$$

was applied on precipitation and temperature over the period of 1986-2016. Where (S)*, S, $\eta$ and $\tilde{\eta}$ represents standardized anomaly of the climate parameter, standard deviation, the magnitude of precipitation or temperature measure for a given year or season and the mean measure of the climate variables over a season or year, respectively.

II. Climate Trend Analysis: If the data has normal distribution, linear regression trend is applied to understand the intensity and tendency of climatic trends using the following relation.

$$
Y=m X i+b
$$


But, since the data distribution is skewed, Mann-Kendall trend analysis was used based on [equation 2.3.2.2.2 to 2.3.2.2.5].

$$
\mathrm{S}=\sum_{i=1}^{n-1} \sum_{j=i+1}^{n} \operatorname{Sgn}(x j-x i) \quad 5
$$

where, $\mathrm{S}$ is the Mann-Kendall's test statistics; $\mathrm{xi}$ and $\mathrm{xj}$ are the sequential rainfall or temperature values in the year $i$ and $j(j>i)$, and $n$ is the length of the time series. The Sgn $(x j-x i)$ is an indicator function that results in the values $-1,0$, or 1 , and it is calculated as

$$
\operatorname{sgn}(x j-x i)=\left(\begin{array}{cccc}
+1 & \text { if } & x j-x i & >0 \\
0 & \text { if } & x j-x i & =0 \\
-1 & \text { if } & x j-x i & <0
\end{array}\right) \quad 6
$$

Then, the slope (change per unit time) is calculated as

$$
Q=\frac{X j-X i}{i-j} \text { for } i=1 \ldots n
$$

where, $x i$ and $x j$ are data values at times $i$ and $j(j>i)$, respectively. The median of these $n$ values of $Q$ is Sen's estimator of slope. Based on equations 7, trend of the climate (specifically trends of rainfall and temperature) over the study areas is determined from 1986-2016.

The process of downscaling and extrapolating method is used for estimating the future climate condition over our study areas extracted from ICPAC climate prediction center.

\subsubsection{Assessment of Malaria Distribution based on the Observed Climate (1986-2016)}

The favorable climatic conditions for transmission of malaria over the study areas are adopted from Grover-Kopek et al. 2006,

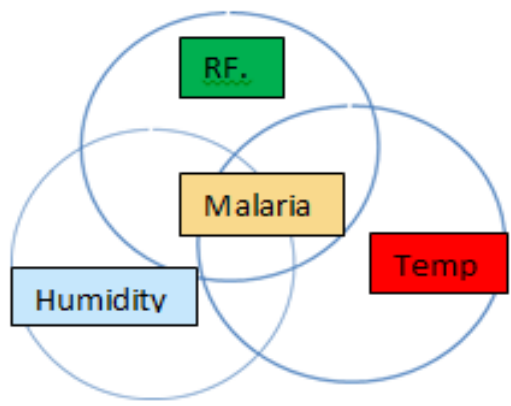

Figure2. Principle of climate driven malaria assessment

which satisfies the following conditions.

1. Monthly precipitation accumulation is at least $80 \mathrm{~mm}$

2. Monthly mean temperature is between $18^{\circ} \mathrm{C}$ and $32^{\circ} \mathrm{C}$ and

3. Monthly mean relative humidity is at least $60 \%$.

On the basis of the above principle, the assessment of climate caused malaria distribution was verified on two data sets.

\subsection{Procedure for Demonstrating Climate-Malaria Information}

Maps done with GIS or other related software are used to display malaria distribution information if the climate data is spatially continuous. But for point station (few numbers of station data e.g. in our case two stations) the above means of displaying malaria information is unfavorable. Therefore, in this research, we designed and undergone a certain processes and procedures to evaluate and display climate suitability for malaria incidence over areas of point location. Here, we choose tabular form of information displaying approach show the assessment of malaria distribution, for point location and for a few numbers of very far apart located weather stations, rather than displaying the assessment 
results on maps. This procedure is based on a simple logical algorithm used to intersect the three necessary conditions that satisfy the principle stated by Grover-Kopek et al. 2006. This procedure is carried out with the data flittering tools found on excel worksheet.

\subsection{Composite Analysis of Climate Variability Versus Malaria Incidence Intensity}

This method is used to compare the effect of climate variability in relation to malaria existence likelihood per year. This is conducted through comparing time series analysis/trend of Rainfall and temperature with the trend of fraction of malaria incidence per year given by

$$
\mathrm{I}=\frac{n}{12}
$$

Where 'I' represents unit-less fraction indicating the intensity of persisting malaria per year; and $n$ represents number of months that climate was suitable for malaria occurrence possibility. 'I' ranges from 0 to 1 , in magnitude; where 0 indicates no chance of malaria incidence and 1 indicates strong expectancy of malaria prevalence throughout the year. In addition, correlation coefficient r(uy)

$$
\boldsymbol{r u \boldsymbol { y }}=\frac{\sum_{i=1}^{n} \text { uiyi }-n \overline{\mathrm{u}} \overline{\mathrm{y}}}{\left.\sqrt{(} \sum_{i=1}^{n}(u i)^{2}-n(\overline{\mathrm{u}})^{\wedge} 2\right)\left(\sum_{i=1}^{n} y i^{2}-n \overline{\mathrm{y}}^{\wedge} 2\right)}
$$

tells us about the strength of the relation between two variables., in our case: we calculated and analyzed the correlation between malaria occurrence frequency 'I' with temperature and rainfall variability on seasonal base.

\subsection{Future Prospect of Malaria Transmission Over the Study Areas}

To carry out future prospect of malaria transmission, we modified our data based on the estimate of climate projections for different scenarios, extracted from published papers, as a secondary data source and climate data extracted from ICPAC climate prediction center. This, approach enable us to observe the future climate condition roughly with respect to time and spatial elevation. Next, we follow the same method as we did for assessment of malaria transmission in the past (1986-2106) to demonstrate the future malaria distribution based on climate suitability logic. Such that this approach is used to potentially indicate the future prospect of malaria appearance likelihood over higher altitude places.

\section{RESUlT AND DISCUSSION}

\subsection{Climate Assessment and Characterization for Combolcha District}

\subsubsection{Annual Precipitation Characteristics of Combolcha (1986-2016)}

As shown on figure 1, Combolcha weather station exhibited bi-modal type of rain fall characteristics for the year 1986-2016.

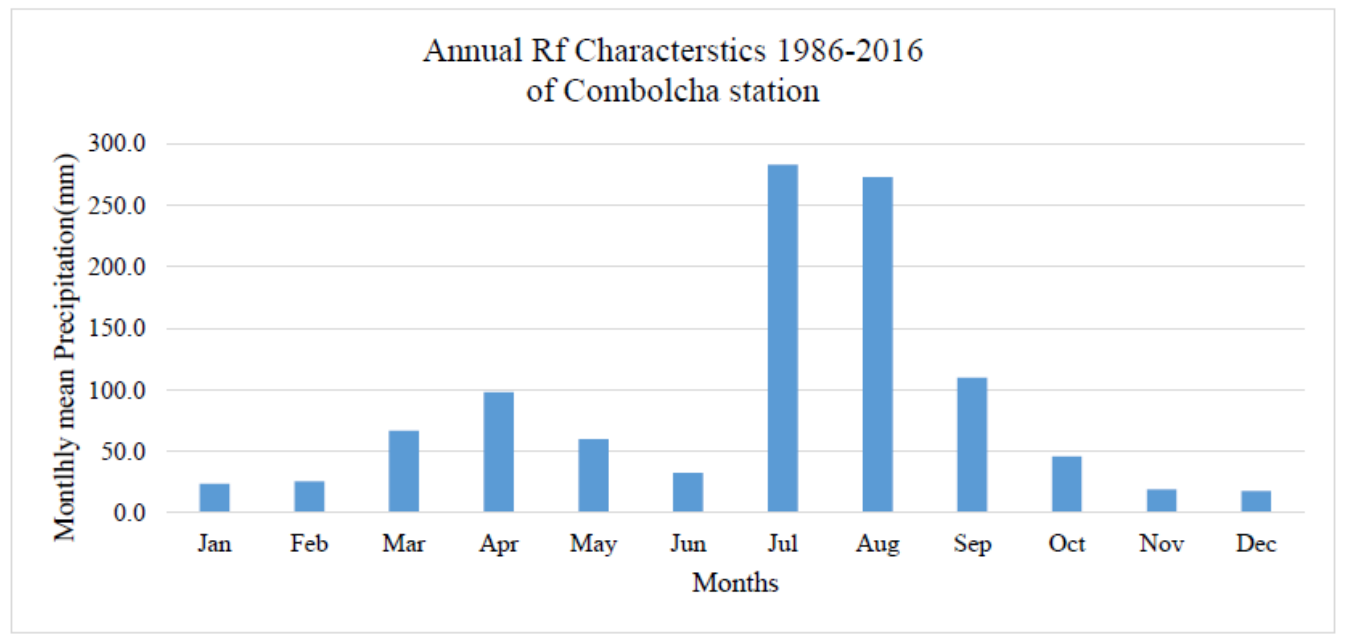

Figure1. Annual Precipitation characteristics of Combolcha (1986-2016) 
That means, there have been two rainy seasons per year. The first rainy season starts from March and prevails up to May with the pick on April with mean value equal to $99.0 \mathrm{~mm}$. The second rainy season starts on June and extends up to September with peak values observed on July and August. With this climatic mean, mainly months of April, July, August and September recorded rain fall amount greater than $80.0 \mathrm{~mm}$ which has appositive impact for transmission of malaria disease.

Long-Range Mean Monthly Temperature Profile during 1986-2016 Over Combolcha

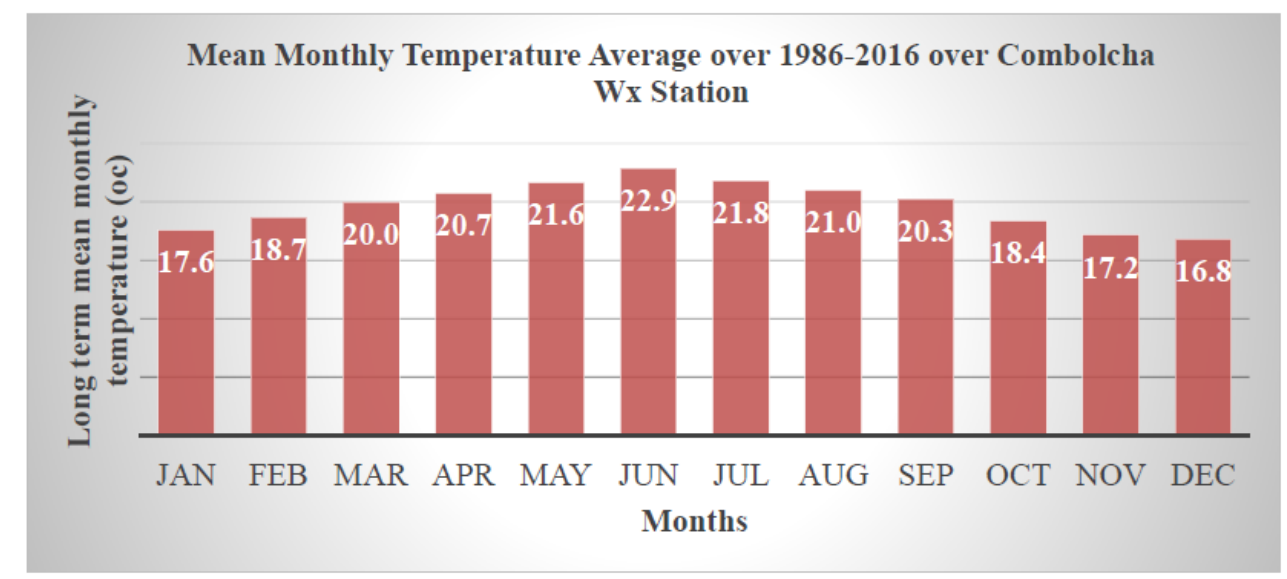

Figure2. Long Range Mean Monthly Temperature Profile over 1986-2016 over Combolcha

The above figure represents the long-range temperature of monthly mean averaged over 31 years. The peak is recorded on June with value $22.9^{\circ} \mathrm{c}$ and the smallest is on December, $16.8^{\circ} \mathrm{c}$. From the malaria occurrence perspective, months of FMAM and JJASO favor the conducive condition based on the principle $\left(>18^{\circ} \mathrm{c}\right)$. The rest of the months, NDJ do not satisfy the condition.

\subsubsection{Seasonal Rain Fall Anomaly for Combolcha (1986-2016)}

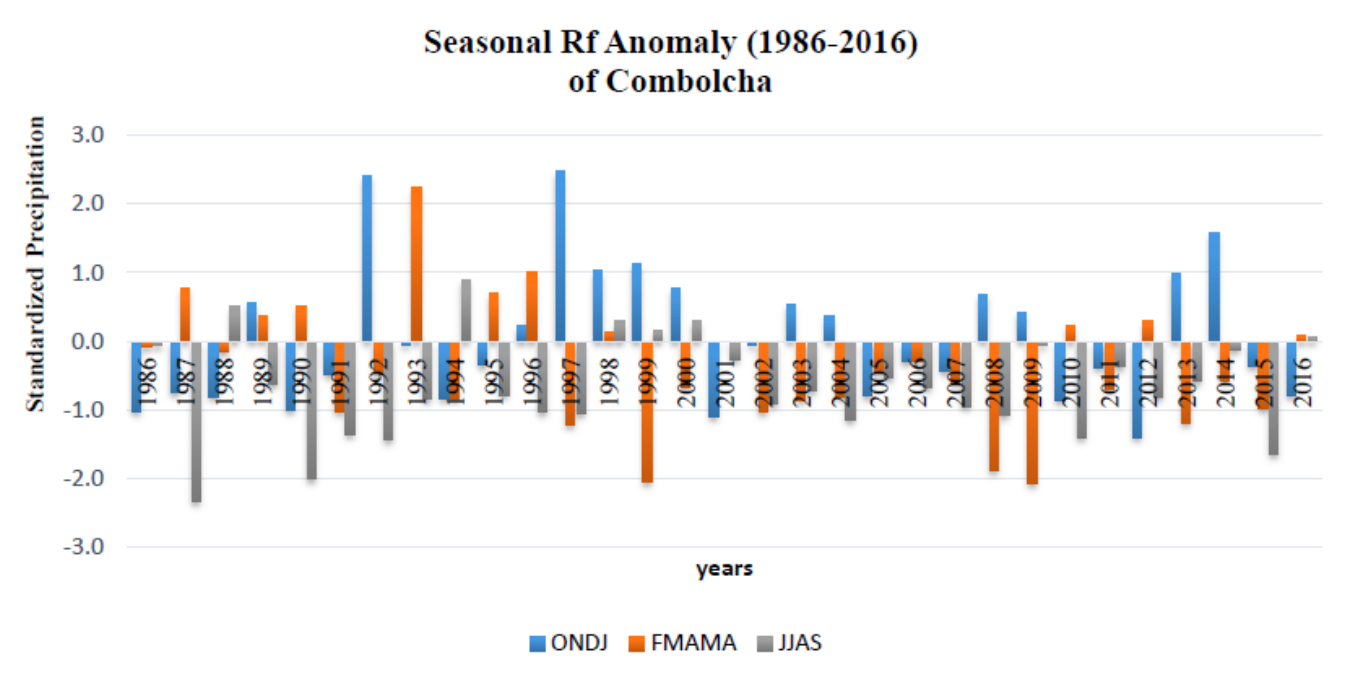

Figure3. Seasonal Rain Fall Standardized Anomaly for Combolcha (1986-2016)

The above figure 3 depicts variation of standardized precipitation anomalies from the mean climatic condition for three seasons ONDJ (Bega), FMAM (Belg) and JJAS (Kiremit).

For several years out of the 30 climatic years (1986-2016) ONDJ showed a negative deviation from the mean with value approximately from -0.5 to -1.5 in the year of 2012. In contrast, the number of years with the positive deviation is less than half though the standardized deviation magnitude is strong (+2.2) in 1992, 1997 and 2014 which is virtually greater than the negative deviation. Therefore. On this season (ONDJ) the positive impact of climate is very limited except for the years associated with extreme positive deviation. Whereas, FMAM and JJAS mostly exhibited a negative deviation from the mean condition starting from the year 1997 up to 2009. Thus, negative impact is expected over these particular years. 


\subsection{Annual and Seasonal Precipitation Trend for Combolcha}

The following figure shows the overall trend of annual and seasonal precipitation over Combolcha from 1986-2016.

Virtually, a decreasing trend in precipitation is observed on annual base. However, this may or may not affect the occurrence of malaria since

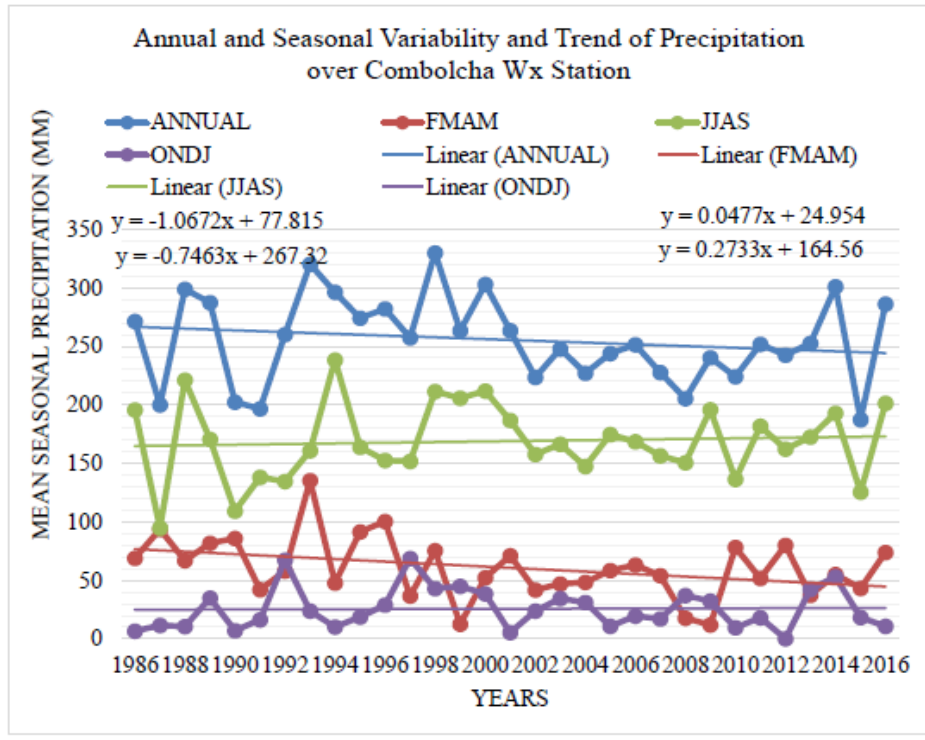

Figure4. Annual seasonal Precipitation Trend and variability for Combolcha (1986-2016)

monthly cumulative rain fall may or may not significantly decrease bellow $80 \mathrm{~mm}$. So, we shall see the impact of precipitation on malaria in detail on seasonal and monthly base as provided in the next sentences. On ONDJ (Bega) season for Comblocha, one can see from the sketch, the variability is drawn with time series graph. With a period of five years, the graph crosses the mean condition one time up and the other time down. This shows there existed a five-year rain fall variability for ONDJ over Combolcha. In addition, there were a slight increase in precipitation trend on this season. This fact may have a positive impact on malaria transmission such that extension of malaria season apart from the usual period/months is expected. On FMAM (Belg) season, unlike ONDJ, the variability had irregu- lar pattern on this season. Once the rain fall performance increased from the mean, it takes longer time to decrease again; until that there is moderate variation (with small amplitude) without intercepting the mean value. The same is true on the decreasing rain fall performance. Apart from this a sharp increasing and decreasing variability with shorter period is observed with extreme values. On the other hand, a significant decreasing trend is observed starting from the year 2010 and onwards. This could result in negative impact for malaria distribution on particularly on FMAM season.

On JJAS (Kiremt) season, the rain fall variability, in general, had regular pattern with period of five years on average. Despite a slight increasing trend in precipitation from 1986-2016, there was prolonged decrease for the period starting from 2002 up to 2008. This situation could rise unfavorable condition for malaria distribution on this season for the prescribed period (2000-2008).

\subsection{Seasonal Temperature Anomaly and Trend for Combolcha}

The figure provided next tell us information about how frequently the temperature deviates from the mean and its trend on seasonal base. This graph (figure 4.1.1.e) shows seasonal temperature deviation from the seasonal mean and trend of each season for temperature for Combolcha station. As can be seen from the graph the temperature trend showed increasing though out the whole seasons. But, the increase was pronounced on FMAM season for Combolcha. Especially strong positive deviation is started from 2000 and persisted to 2016. Further the years2013, 2015 and 2016 recorded extreme event in temperature for the stations. This event could favor a suitable condition for malaria transmission following the rainy seasons, FMAM and JJAS.

On the other hand, before the year 2000 there, mostly, was a temperature record below the mean for FMAM and JJAS for Combolcha. This had a negative impact on malaria distribution on the respective 
years. However, there were some numbers of years which showed a positive deviation that could favor malaria prevalence on Combolcha on the season of FMAM (Belg), before 2000. In similar, 2009, 2010, 2013 and 2016 were the years exhibited as a suitable year for malaria occurrence on the Belg season (FMAM), on the basis of temperature suitability.

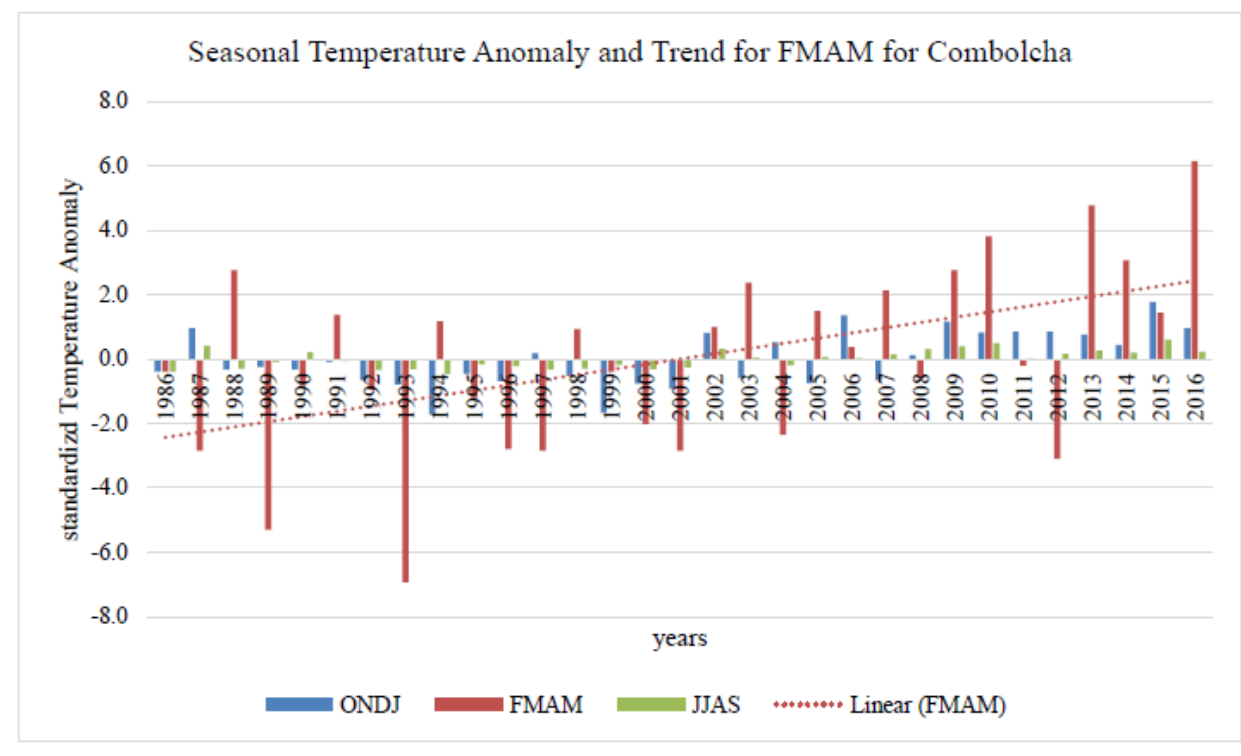

Figure5. Seasonal Temperature Anomaly for Combolcha (1986-2016)

On the other hand, before the year 2000 there, mostly, was a temperature record below the mean for FMAM and JJAS for Combolcha. This had a negative impact on malaria distribution on the respective years. However, there were some numbers of years which showed a positive deviation that could favor malaria prevalence on Combolcha on the season of FMAM (Belg), before 2000. In similar, 2009, 2010, 2013 and 2016 were the years exhibited as a suitable year for malaria occurrence on the Belg season (FMAM), on basis of temperature suitability.

\subsection{Summary of Climate Variability and Trend Over Combolcha}

The following table provides the summary of climate variability and trend over Combolcha station with seasonal and annual base, for precipitation and temperature. The coefficient of variation with rank of variability strength and the trend with Z-test and the slope are given in the table. The Z-test tells us the significance of the trend on the range ( $-1.96<=$ Z-test $<=1.96$ with $5 \%$ uncertainty).

Table1. Summary of Coefficient of variation and Trend for RF and Temperature over Combolcha Station

\begin{tabular}{|c|c|c|c|c|c|c|}
\hline Station & Element & Season & \multicolumn{2}{|c|}{$\begin{array}{c}\text { Coefficient of } \\
\text { Variation }\end{array}$} & Z-test & S.slope \\
\hline \multirow{8}{*}{ Combolcha } & \multirow[t]{4}{*}{$\mathrm{RF}$} & ONDJ & $75.0 \%$ & $\begin{array}{l}\text { Rank } \\
\text { Extremely } \\
\text { high }\end{array}$ & 0.816 & 0.088 \\
\hline & & FMAM & $53.7 \%$ & V. high & -1.462 & -0.227 \\
\hline & & JJAS & $25.8 \%$ & Moderate & 1.428 & 0.334 \\
\hline & & Annual & $23.6 \%$ & Moderate & -1.258 & -0.195 \\
\hline & & ONDJ & $17.5 \%$ & Low & 2.414 & 0.110 \\
\hline & Temp. & FMAM & $17.6 \%$ & Low & 2.636 & $(0.138)$ \\
\hline & & JJAS & $17.8 \%$ & Low & 3.502 & $(0.140$ \\
\hline & & Annual & $17.5 \%$ & Low & 3.773 & 0.378 \\
\hline
\end{tabular}

As seen on the above table, the result shows that the variability of precipitation is extremely high on ONDJ with $75.0 \%$ and relatively small slope magnitude implies less effect on malaria transmission 
on this season. Again, on FMAM very high variability, $53.7 \%$, in precipitation together with moderate slope implies medium effect on malaria distribution on this season. FMAM variability. The slope is low on ONDJ, moderate on FMAM and strong on JJAS, relatively. This implies the impact of precipitation on malaria prevalence is rare on dry season (ONDJ) due to low slope of trend; and but there may be a chance of favorable precipitation condition for malaria occurrence due to extremely high variability. And on the small rainy season (FMAM), the fluctuation of malaria prevalence could highly be influenced by medium-strong increasing /decreasing trend and very high rain fall variability. On the other hand, on JJAS and Annual base the fluctuation of malaria transmission remains stable (slightly affected) due to moderate variability and low rain fall trend. However, on JJAS there was a strong increasing trend on precipitation that could rise significant increase in malaria incidence if and only if the temperature is supportive. In case of the temperature, the variability is low implies that it is stable. And the slope is increasing for all the seasons and the annual base. The positive slope along with low variability implies stabile increasing trend of temperature on all seasons. This condition could rise a strong positive impact on malaria transmission if the rain fall is supportive for all seasons. Otherwise the effect remains pronounced primarily on JJAS and secondly on FMAM since these were the seasons usually thought to have adequate rainfall for malaria prevention/anticipation.

\section{Climate Characteristics of Debark District}

\subsection{Annual Precipitation Characteristics of Debark}

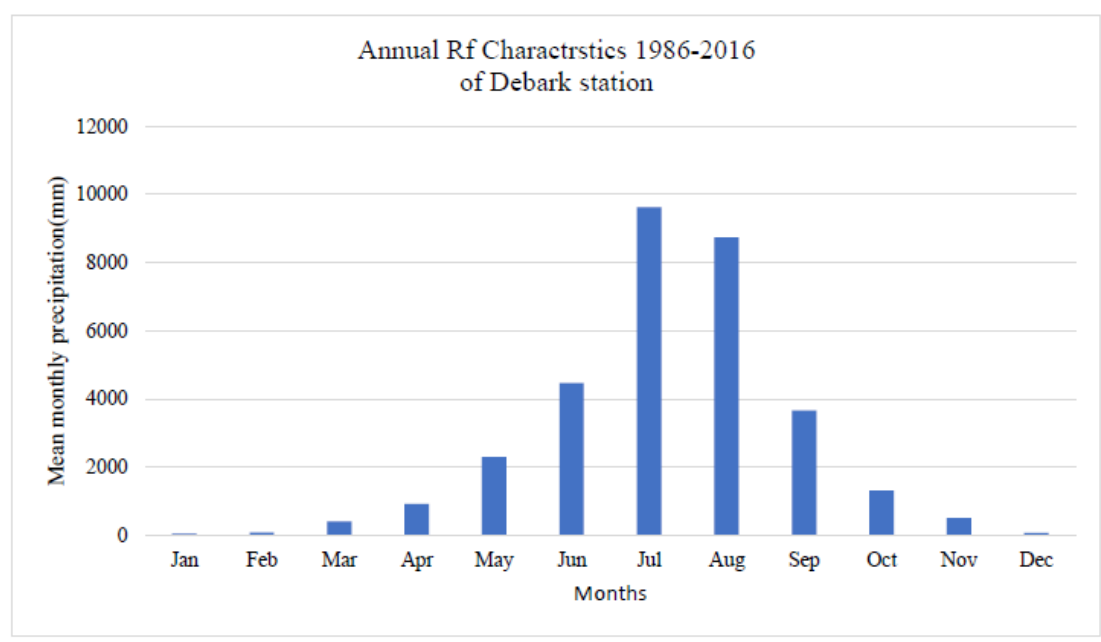

Figure6. Annual Precipitation characteristics of Debark (1986-2016)

As shown on fig.6, Debark weather station exhibited mono-modal type of rain fall characteristics for the year 1986-2016. That means, there have been one rainy season per year. The rainy season starts from June and persists up to September with the picks observed on July and August. With this climatic mean, mainly months of July, August and September recorded rain fall amount greater than $80.0 \mathrm{~mm}$ which has appositive impact for transmission of malaria disease.

\subsection{Long Range Mean Monthly Temperature Profile Over Debark}

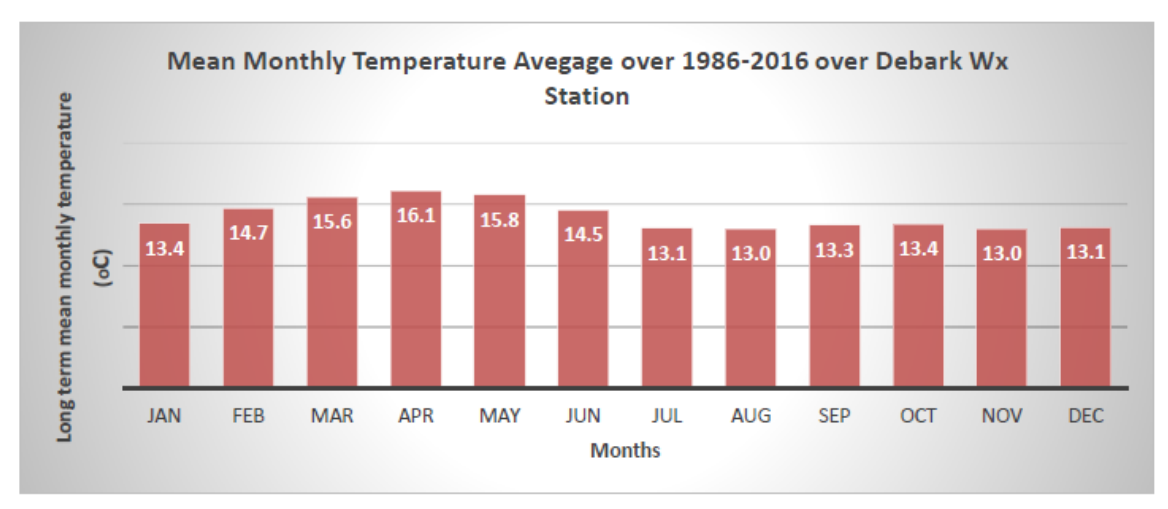

Figure7. Long Range Mean Monthly Temperature Profile over 1986-2016 over Debark 
As shown on the above graph, the mean monthly temperature reaches peak on April. The second peak is observed on may. The smallest record is exhibited on November and December. Based on this mean record in temperature average over 1986-2016, no one month could full fill the criteria for malaria transmission. But, on the former two months the condition might probably be favorable for malaria transmission based on separate years (1986-2016). In contrast, the temperature, on the latter two months could lead to a strong negative impact on malaria transmission throughout the year 19862016.

\subsection{Seasonal Rain Fall Anomaly for Debark (1986-2016)}

The following figure 8 depicts variation of standardized precipitation anomalies from the mean climatic condition for three seasons ONDJ (Bega), FMAM (Belg) and JJAS (Kiremit).

For more than half number of years out of the 31 climatic years (1986-2016) ONDJ showed a negative deviation for several years. But 1988, 1997, 1998, 1999, 2000, 2015 and 2016 exhibited a positive deviation. On the other hand, FMAM showed negative deviation on 1988-1994 and 20022007; and positive deviation on 1995-2001 and 2010-2016. For the aforementioned periods precipitation have favored negatively and positively for malaria distribution, respectively. But, JJAS have showed a negative deviation for several years except few years like: 1988, 1989, 2007, 2011, 2015 and 2016. Since, the amplitude of the

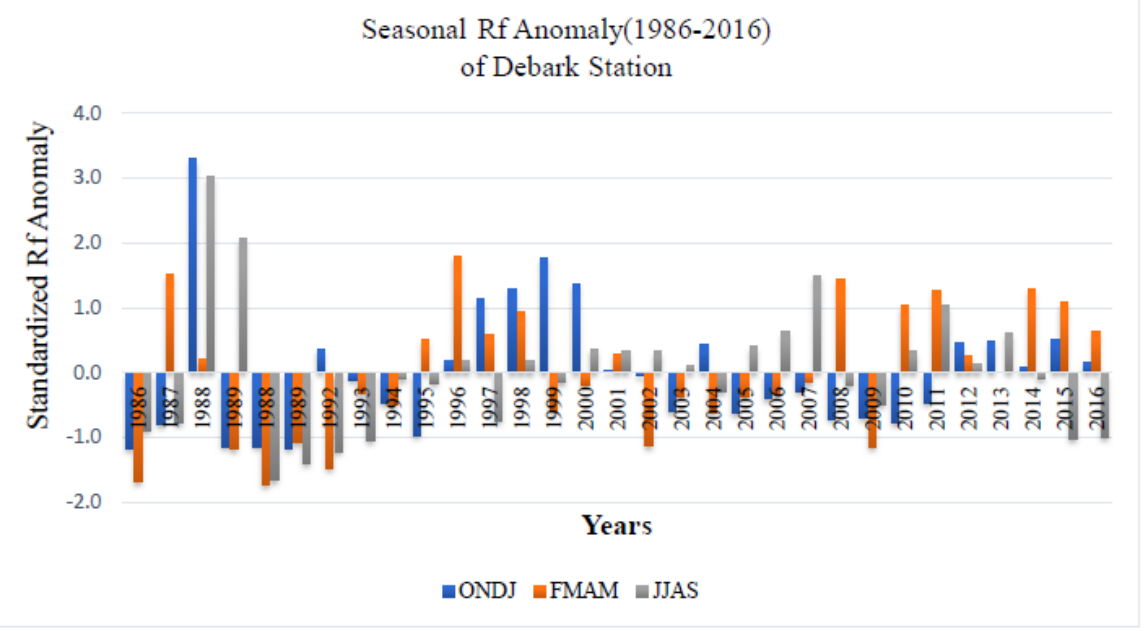

Figure8. Seasonal Rain Fall Anomaly for Debark (1986-2016)

negative deviation is relatively small the chance of malaria occurrence is only slightly affected.

Except this fact, the precipitation performance had a positive impact on malaria occurrence.

\subsection{Annual and Seasonal Precipitation Trend for Debark (1986-2016)}

The following figure shows the overall trend of precipitation over Debark station from 1986 to 2016. Virtually, an increasing trend in precipitation is observed, on annual base. However, this may or may not affect the occurrence of malaria since epidemiology of malaria is primarily rainy season dependent. Thus, the seasonal variations and seasonal trends in precipitation performance need to be treated separately, as in the next paragraphs.

The variability in rain fall performance had a regular pattern on average, but the amplitude of variation decreases from the year of 2000 and onwards 2016. In line with this, there were a slight increase in precipitation trend on this season starting from 2000. This fact may have a positive impact on malaria transmission such that a chance of incidence of malaria is expected as far as the temperature and humidity conditions are fulfilled; otherwise not expected.

In similar fashion to Combolcha, Debark also showed irregular rain fall variability over FMAM. Once the rain fall performance increased from the mean, it takes longer time to decrease again; until that there is moderate variation without intercepting the mean interval. The same is true on the decreasing rain fall performance. Apart from this a sharp increasing and decreasing variability with shorter period is observed with extreme values. 


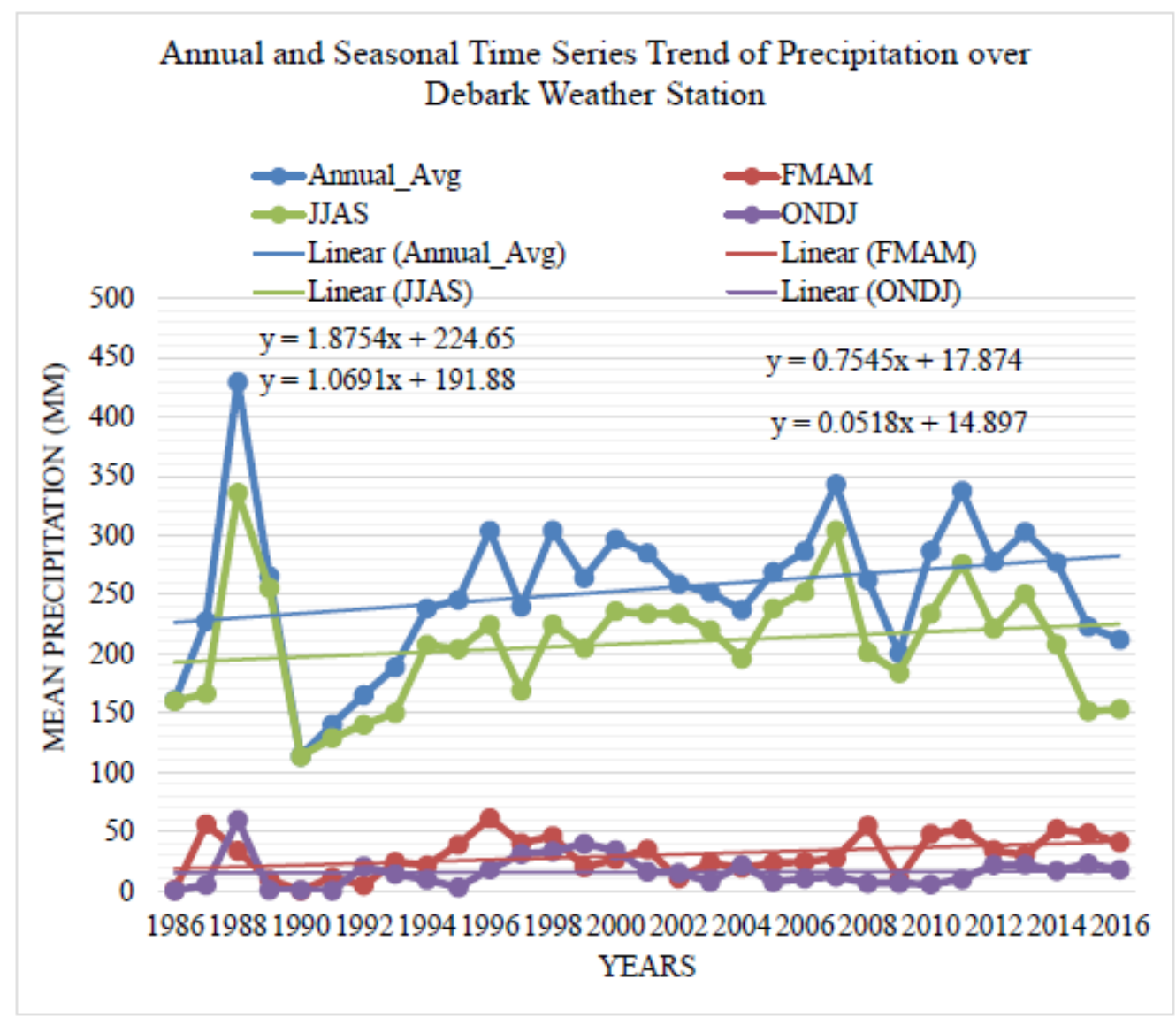

Figure9. Seasonal and Annual rain Fall Variability and Trend of Combolcha (1986-2016)

On the other hand, a moderate increasing trend is observed starting from the year 20005 and onwards. This could result in positive impact for malaria distribution on FMAM season over the recent years.

As one can see from the sketch, the rain fall variability over JJAS, in general, had regular pattern with period of five years on average. But, at the beginning of the first two five years (1986-1990 and 19911995) the variation amplitude was strong as compared to next two five years (1996-2000 and 20012005). Again, the amplitude of variation rises moderately for the last two five years (2006-2010 and 2011-2016). For the period starting from 2002 up to 2008 the decrease was prolonged. On the other hand, a slight increasing trend is observed starting from 2005 and onwards. This situation could rise favorable condition for malaria distribution on this season for the prescribed period (2005-2016).

\subsection{Seasonal Temperature Anomaly and Trend for Debark}

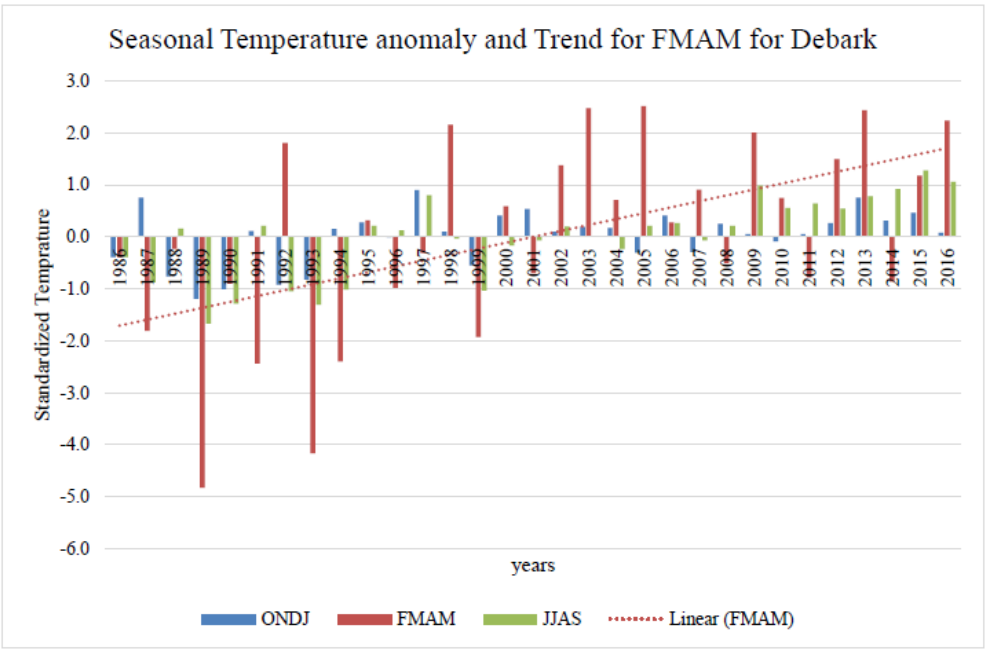

Figure10. Seasonal Temperature Anomaly for Combolcha and Debark (1986-2016) 
The preceding graph provides seasonal temperature deviation from the seasonal mean and trend of each season for temperature on Debark station. As can be seen from the graph the temperature trend showed increasing though out the whole seasons. But, the increase was pronounced on FMAM season as well. Especially strong positive deviation is started from 2000 and persisted to 2016. Further the years 2015 and 2016 recorded extreme event in temperature. This favored a suitable condition for malaria transmission following the rainy seasons, FMAM and JJAS. On the other hand, before the year 2000 there was a temperature record below the mean for FMAM and JJAS season. This had a negative impact on malaria distribution on the respective years.

\subsection{Summary of Climate Trend and Variability Over Debark}

The following table provides the summary of climate variability and trend over Debark.

Table2. Summary of Coefficient of variation and Trend for RF and Temperature on Debark

\begin{tabular}{|c|c|c|c|c|c|c|}
\hline Station & Element & Season & \multicolumn{2}{|c|}{ Coefficient of Variation } & Z-test & S.slope \\
\hline \multirow{10}{*}{ Debark } & \multirow{6}{*}{ RF } & \multirow{3}{*}{ ONDJ } & & Rank & \multirow{3}{*}{1.360} & \multirow{3}{*}{1.062} \\
\hline & & & $96.4 \%$ & Extremely & & \\
\hline & & & & high & & \\
\hline & & FMAM & $45.6 \%$ & V. high & 2.312 & 3.500 \\
\hline & & JJAS & $27.5 \%$ & Moderate & 1.428 & 6.652 \\
\hline & & Annual & $27.6 \%$ & Moderate & 1.360 & 8.282 \\
\hline & & ONDJ & $17.7 \%$ & Low & 2.414 & 0.110 \\
\hline & Temp. & FMAM & $17.9 \%$ & Low & $(2.636)$ & 0.138 \\
\hline & & JJAS & $17.9 \%$ & Low & 3.502 & 0.140 \\
\hline & & Annual & $17.7 \%$ & Low & 3.773 & 0.378 \\
\hline
\end{tabular}

Table 2 shows the coefficient of variation with rank of variability strength and the trend with Z-test and the slope. The Z-test tells us the significance of the trend on the range $(-1.96<=\mathrm{Z}$-test $<=1.96)$. Thus, this result shows that the variability of precipitation is extremely high on ONDJ with $96.4 \%$ and FMAM very high on FMAM $45.6 \%$ variability. The slope is low on ONDJ, moderate on FMAM and strong on JJAS, relatively. This implies the impact of precipitation on malaria prevalence on these seasons is rare on dry season (ONDJ) due to low slope of trend and extremely high variability. And on the small rainy season (FMAM), malaria prevalence is highly influenced by medium-strong increasing trend and very high rain fall variability. On the other hand, on JJAS and Annual base the fluctuation of malaria transmission remains stable (slightly affected) due to moderate variability and low rain fall trend. However, on JJAS there was a strong increasing trend on precipitation that could rise significant increase in malaria incidence if and only if the temperature is supportive. In case of the temperature, the variability is low implies that it is stable. And the slope is increasing for all the seasons and the annual base. The positive slope along with low variability implies stabile increasing trend of temperature on all seasons. This condition could rise a strong positive impact on malaria transmission if the temperature at the weather station height is suitable for existence of malaria.

Otherwise the effect remains pronounced primarily on JJAS and secondly on FMAM since these were the seasons usually thought to have adequate rainfall for malaria anticipation. In addition, the temperature with low variability implies that there was no or very little fluctuation in malaria transmission on the area where the condition is met. 
5. Assessment of Climate Impact on Malaria Transmission Over Combolcha WOREDA

\subsection{Malaria Climatic Suitability (1986-2016) for Combolcha District}

As shown on the following table, the climate variables which are determinant for malaria transmission are brought with the necessary threshold values. These are monthly precipitation cumulative (with blue color), mean monthly temperature threshold 18-32 oc (with red color) and monthly average relative humidity greater than $60 \%$ (with grey color).

Table3. Malaria Conducive Climate Condition (1986-2016) for Combolcha

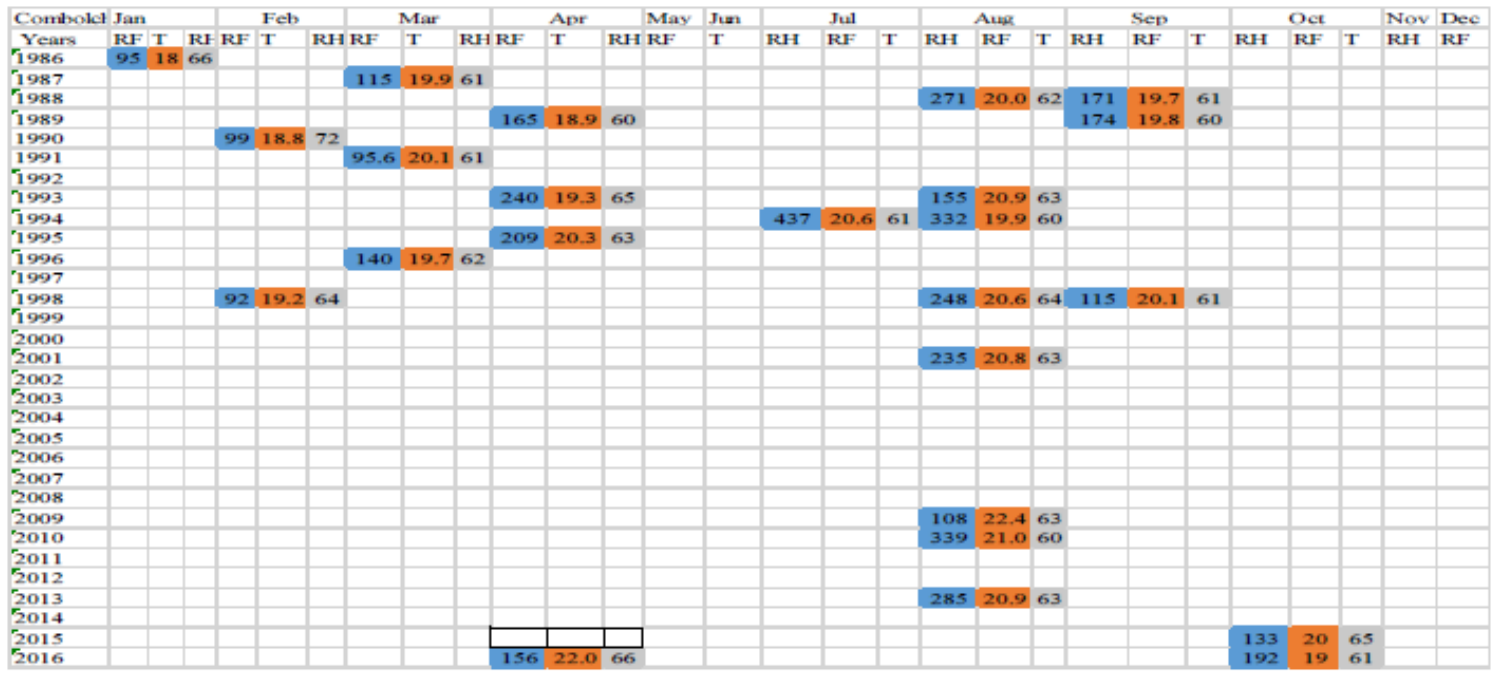

Based on this principle, the year before 1998 there was a possibility of malaria transmission twice per year. These months were mainly February to April. The second malaria transmission months were August and September. Generally, the malaria transmission season was seen following the first rainy season (February to April) and the second rainy season (August and September). Meanwhile, the month of May to June and November to December were observed transition periods or malaria free months for the whole years. Besides, January and July rarely exhibited the favorable condition for malaria transmission as far as the onset of the rainy seasons started early, see 1986 and 1994 respectively. On the other hand, after the year of 1998, the conducive conditions for malaria prone months are limited only to the second rainy season (August and September). Apart from this, the malaria transmission season was elongated to the first month of the next season (October), in the year 2015 and 2016.

\subsection{Climate Impact on Malaria Over Debark using Station Data}

Here, we first used station data collected from Debark weather station for similar interval of time (1986-2016). Secondly, we also assessed climate impact on malaria with gridded/ ENACTS data set with similar time interval to station data. And observe the difference of the results obtained by using these two data sets. To the same manner we did for Combolcha, the cumulative monthly precipitation, the mean monthly temperature and the monthly average of relative humidity were evaluated whether the recorded values met the threshold level or not, as per the principle.

\subsection{Malaria Climatic Suitability (1986-2016) for Debark Station}

As shown on the following table 4, the climate variables which are determinant for malaria transmission are brought with the necessary threshold values. These are monthly precipitation cumulative (with blue color), mean monthly temperature threshold 18-32 oc (with red color) and relative humidity greater than $60 \%$ with light grey color.

The following table provides assessment of climate suitability for malaria prevalence and distribution based on Debark station climate data. Unfortunately, none of the months and years given above were identified to satisfy the climate conducive condition for malaria epidemiology. This is due the fact that when we get higher and higher in altitude the temperature measure decreases with elevation. So, the main reason for the existence of unfavorable climate condition for malaria transmission over Debark 'town' ( $2836.0 \mathrm{~m}$ elevation) was due to the temperature found to be below the minimum threshold value $(<18 \mathrm{co})$ for the whole years. 
Assessment and Projection of Climate Change Impacts on Malaria Distribution in Ethiopia: Case of Combolcha and Debark Districts

Table4. Climate Conducive Malaria Occurrence (1986-2016) for Debark

\begin{tabular}{|c|c|c|c|c|c|c|c|c|c|c|c|c|c|c|c|c|c|c|c|c|c|c|c|c|c|c|c|c|}
\hline \multicolumn{2}{|c|}{ Debark S: Jan } & \multirow[b]{2}{*}{$\mathrm{T}$} & \multirow{2}{*}{$\mathrm{RH}$} & \multicolumn{3}{|c|}{ Feb } & \multicolumn{2}{|c|}{ Mar } & \multicolumn{3}{|c|}{ Apr } & \multicolumn{3}{|c|}{ May Jun } & \multirow{2}{*}{$\begin{array}{l}\text { Jul } \\
\mathrm{RH}\end{array}$} & \multirow[b]{2}{*}{ RF } & \multirow[b]{2}{*}{$\mathrm{T}$} & \multicolumn{2}{|l|}{ Aug } & & \multicolumn{2}{|l|}{ Sep } & \multicolumn{3}{|c|}{ Oct } & & \multicolumn{2}{|c|}{ No Dec } \\
\hline Years & RF & & & RF & & RH & RF & $\mathrm{T}$ & $\mathrm{RH}$ & $\mathrm{RF}$ & $\mathrm{T}$ & $\mathrm{RH}$ & RF & $\mathrm{T}$ & & & & $\mathrm{RH}$ & RF & $T$ & $\mathrm{RH}$ & RF & $\mathrm{T}$ & & RF ] & $\mathrm{T}$ & & RF \\
\hline 1986 & $\mathbf{x}$ & $\mathbf{x}$ & $\mathbf{x}$ & $\mathbf{x}$ & $\mathbf{x}$ & $\mathbf{x}$ & $\mathbf{x}$ & $\mathbf{x}$ & $\mathbf{x}$ & $\mathbf{x}$ & $\mathbf{x}$ & $\mathbf{x}$ & $\mathbf{x}$ & $\mathbf{x}$ & $\mathbf{x}$ & $\mathrm{x}$ & $\mathbf{x}$ & $\mathbf{x}$ & $\mathbf{x}$ & $\mathbf{x}$ & $\mathbf{x}$ & $\mathbf{x}$ & $\mathbf{x}$ & $\mathbf{x}$ & $\mathrm{x}, \mathrm{z}$ & $\mathbf{x}$ & $\mathbf{x}$ & $\mathbf{x}$ \\
\hline 1987 & $\mathbf{x}$ & $\mathbf{x}$ & $\mathbf{x}$ & $\mathrm{x}$ & $\mathbf{x}$ & $\mathrm{x}$ & $\mathbf{x}$ & $\mathbf{x}$ & $\mathbf{x}$ & $\mathbf{x}$ & $\mathbf{x}$ & $\mathbf{x}$ & $\mathbf{x}$ & $\mathbf{x}$ & $\mathbf{x}$ & $\mathbf{x}$ & $\mathbf{x}$ & $\mathbf{x}$ & $\mathbf{x}$ & $\mathbf{x}$ & $\mathbf{x}$ & $\mathbf{x}$ & $\mathbf{x}$ & $\mathbf{x}$ & $x=$ & $\mathbf{x}$ & $\mathbf{x}$ & $\mathbf{x}$ \\
\hline 1988 & $\mathbf{x}$ & $\mathbf{x}$ & $\mathbf{x}$ & $\mathbf{x}$ & $\mathbf{x}$ & $\mathbf{x}$ & $\mathbf{x}$ & $\mathbf{x}$ & $\mathbf{x}$ & $\mathbf{x}$ & $\mathbf{x}$ & $\mathbf{x}$ & $\mathbf{x}$ & $\mathbf{x}$ & $\mathbf{x}$ & $\mathbf{x}$ & $\mathbf{x}$ & $\mathbf{x}$ & $\mathbf{x}$ & $\mathbf{x}$ & $\mathbf{x}$ & $\mathbf{x}$ & $\mathbf{x}$ & $\mathbf{x}$ & $x=$ & $\mathbf{x}$ & $\mathbf{x}$ & $\mathbf{x}$ \\
\hline 1989 & $\mathbf{x}$ & $\mathbf{x}$ & $\mathbf{x}$ & $\mathbf{x}$ & $\mathbf{x}$ & $\mathbf{x}$ & $\mathbf{x}$ & $\mathbf{x}$ & $\mathrm{x}$ & $\mathbf{x}$ & $\mathbf{x}$ & $\mathbf{x}$ & $\mathbf{x}$ & $\mathbf{x}$ & $\mathrm{x}$ & $\mathrm{x}$ & $\mathbf{x}$ & $\mathrm{x}$ & $\mathbf{x}$ & $\mathbf{x}$ & $\mathbf{x}$ & $\mathbf{x}$ & $\mathbf{x}$ & $\mathbf{x}$ & $\mathbf{x}$ & $\mathrm{x}$ & $\mathbf{x}$ & $\mathbf{x}$ \\
\hline 1990 & $\mathbf{x}$ & $\mathbf{x}$ & $\mathbf{x}$ & $\mathbf{x}$ & $\mathbf{x}$ & $\mathbf{x}$ & $\mathbf{x}$ & $\mathbf{x}$ & $\mathbf{x}$ & $\mathbf{x}$ & $\mathbf{x}$ & $\mathbf{x}$ & $\mathbf{x}$ & $\mathbf{x}$ & $\mathrm{x}$ & $\mathrm{x}$ & $\mathbf{x}$ & $\mathbf{x}$ & $\mathbf{x}$ & $\mathbf{x}$ & $\mathbf{x}$ & $\mathbf{x}$ & $\mathbf{x}$ & $\mathbf{x}$ & $\mathbf{x}$ & $\mathbf{x}$ & $\mathbf{x}$ & $\mathbf{x}$ \\
\hline 1991 & $\mathbf{x}$ & $\mathrm{x}$ & $\mathbf{x}$ & $\mathbf{x}$ & $\mathbf{x}$ & $\mathbf{x}$ & $\mathbf{x}$ & $\mathbf{x}$ & $\mathbf{x}$ & $\mathbf{x}$ & $\mathrm{x}$ & $\mathbf{x}$ & $\mathbf{x}$ & $\mathbf{x}$ & $\mathbf{x}$ & $\mathbf{x}$ & $\mathbf{x}$ & $\mathrm{x}$ & $\mathbf{x}$ & $\mathbf{x}$ & $\mathbf{x}$ & $\mathbf{x}$ & $\mathbf{x}$ & $\mathbf{x}$ & $\mathrm{x}$ & $\mathbf{x}$ & $\mathrm{x}$ & $\mathbf{x}$ \\
\hline 1992 & $\mathbf{x}$ & $\mathbf{x}$ & $\mathbf{x}$ & $\mathrm{x}$ & $\mathbf{x}$ & $\mathrm{x}$ & $\mathrm{x}$ & $\mathbf{x}$ & $\mathbf{x}$ & $\mathbf{x}$ & $\mathbf{x}$ & $\mathbf{x}$ & $\mathbf{x}$ & $\mathrm{x}$ & $\mathrm{x}$ & $\mathrm{x}$ & $\mathbf{x}$ & $\mathrm{x}$ & $\mathrm{x}$ & $\mathrm{x}$ & $\mathbf{x}$ & $\mathrm{x}$ & $\mathbf{x}$ & $\mathbf{x}$ & $x$, & $\mathbf{x}$ & $\mathrm{x}$ & $\mathbf{x}$ \\
\hline 1993 & $\mathbf{x}$ & $\mathbf{x}$ & $\mathrm{x}$ & $\mathrm{x}$ & $\mathbf{x}$ & $\mathrm{x}$ & $\mathbf{x}$ & $\mathbf{x}$ & $\mathbf{x}$ & $\mathbf{x}$ & $\mathrm{x}$ & $\mathbf{x}$ & $\mathbf{x}$ & $\mathbf{x}$ & $\mathbf{x}$ & $\mathrm{x}$ & $\mathbf{x}$ & $\mathbf{x}$ & $\mathbf{x}$ & $\mathrm{x}$ & $\mathrm{x}$ & $\mathbf{x}$ & $\mathbf{x}$ & $\mathbf{x}$ & $\mathbf{x}$ & $\mathbf{x}$ & $\mathrm{x}$ & $\mathrm{x}$ \\
\hline 1994 & $\mathbf{x}$ & $\mathbf{x}$ & $\mathrm{x}$ & $\mathbf{x}$ & $\mathbf{x}$ & $\mathrm{x}$ & $\mathbf{x}$ & $\mathbf{x}$ & $\mathbf{x}$ & $\mathbf{x}$ & $\mathbf{x}$ & $\mathbf{x}$ & $\mathbf{x}$ & $\mathbf{x}$ & $\mathrm{x}$ & $\mathrm{x}$ & $\mathbf{x}$ & $\mathrm{x}$ & $\mathbf{x}$ & $\mathbf{x}$ & $\mathrm{x}$ & $\mathbf{x}$ & $\mathbf{x}$ & $\mathbf{x}$ & $\mathbf{x}$ & $\mathbf{x}$ & $x$ & $\mathbf{x}$ \\
\hline 1995 & $\mathbf{x}$ & $\mathbf{x}$ & $\mathbf{x}$ & $\mathbf{x}$ & $\mathbf{x}$ & $\mathbf{x}$ & $\mathbf{x}$ & $\mathbf{x}$ & $\mathbf{x}$ & $\mathbf{x}$ & $\mathbf{x}$ & $\mathbf{x}$ & $\mathbf{x}$ & $\mathbf{x}$ & $\mathbf{x}$ & $\mathbf{x}$ & $\mathbf{x}$ & $\mathbf{x}$ & $\mathbf{x}$ & $\mathbf{x}$ & $\mathbf{x}$ & $\mathbf{x}$ & $\mathbf{x}$ & $\mathbf{x}$ & $\mathrm{x}$ & $\mathbf{x}$ & $\mathbf{x}$ & $\mathrm{x}$ \\
\hline 1996 & $\mathbf{x}$ & $\mathbf{x}$ & $\mathbf{x}$ & $\mathbf{x}$ & $\mathbf{x}$ & $\mathbf{x}$ & $\mathbf{x}$ & $\mathbf{x}$ & $\mathbf{x}$ & $\mathbf{x}$ & $\mathbf{x}$ & $\mathbf{x}$ & $\mathbf{x}$ & $\mathbf{x}$ & $\mathbf{x}$ & $\mathrm{x}$ & $\mathbf{x}$ & $\mathbf{x}$ & $\mathbf{x}$ & $\mathbf{x}$ & $\mathbf{x}$ & $\mathbf{x}$ & $\mathbf{x}$ & $\mathbf{x}$ & $\mathbf{x}$ & $\mathbf{x}$ & $\mathrm{x}$ & $\mathbf{x}$ \\
\hline 1997 & $\mathrm{x}$ & $\mathrm{x}$ & $\mathrm{x}$ & $\mathrm{x}$ & $\mathbf{x}$ & $x$ & $\mathrm{x}$ & $\mathrm{x}$ & $\mathrm{x}$ & $\mathbf{x}$ & $\mathbf{x}$ & $\mathbf{x}$ & $\mathrm{x}$ & $\mathrm{x}$ & $\mathrm{x}$ & $\mathrm{x}$ & $\mathbf{x}$ & $\mathrm{x}$ & $\mathrm{x}$ & $\mathrm{x}$ & $\mathrm{x}$ & $\mathbf{x}$ & $\mathrm{x}$ & $\mathrm{x}$ & $\mathbf{x}$ & $\mathbf{x}$ & $\mathrm{x}$ & $\mathbf{x}$ \\
\hline 1998 & $\mathbf{x}$ & $\mathbf{x}$ & $\mathbf{x}$ & $\mathrm{x}$ & $\mathbf{x}$ & $\mathrm{x}$ & $\mathbf{x}$ & $\mathbf{x}$ & $\mathbf{x}$ & $\mathbf{x}$ & $\mathbf{x}$ & $\mathbf{x}$ & $\mathbf{x}$ & $\mathbf{x}$ & $\mathrm{x}$ & $\mathrm{x}$ & $\mathbf{x}$ & $\mathbf{x}$ & $\mathbf{x}$ & $\mathbf{x}$ & $\mathbf{x}$ & $\mathbf{x}$ & $\mathrm{x}$ & $\mathbf{x}$ & $\mathbf{x}$ & $\mathbf{x}$ & $\mathrm{x}$ & $\mathbf{x}$ \\
\hline 1999 & $\mathbf{x}$ & $\mathbf{x}$ & $\mathbf{x}$ & $\mathbf{x}$ & $\mathbf{x}$ & $\mathrm{x}$ & $\mathrm{x}$ & $\mathbf{x}$ & $\mathbf{x}$ & $\mathbf{x}$ & $\mathbf{x}$ & $\mathbf{x}$ & $\mathbf{x}$ & $\mathbf{x}$ & $\mathrm{x}$ & $\mathrm{x}$ & $\mathbf{x}$ & $\mathrm{x}$ & $\mathbf{x}$ & $\mathbf{x}$ & $\mathrm{x}$ & $\mathrm{x}$ & $\mathbf{x}$ & $\mathbf{x}$ & $\mathbf{x}$ & $\mathbf{x}$ & $\mathrm{x}$ & $\mathbf{x}$ \\
\hline 2000 & $\mathbf{x}$ & $\mathrm{x}$ & $\mathbf{x}$ & $\mathbf{x}$ & $\mathbf{x}$ & $\mathrm{x}$ & $\mathbf{x}$ & $\mathbf{x}$ & $\mathbf{x}$ & $\mathbf{x}$ & $\mathbf{x}$ & $\mathbf{x}$ & $\mathbf{x}$ & $\mathbf{x}$ & $\mathrm{x}$ & $x$ & $\mathbf{x}$ & $\mathbf{x}$ & $\mathbf{x}$ & $\mathrm{x}$ & $\mathrm{x}$ & $\mathbf{x}$ & $\mathrm{x}$ & $\mathbf{x}$ & $\mathrm{x}$ & $\mathbf{x}$ & $\mathrm{x}$ & $\mathrm{x}$ \\
\hline 2001 & $\mathbf{x}$ & $\mathbf{x}$ & $\mathbf{x}$ & $\mathrm{x}$ & $\mathbf{x}$ & $\mathbf{x}$ & $\mathbf{x}$ & $\mathbf{x}$ & $\mathbf{x}$ & $\mathbf{x}$ & $\mathbf{x}$ & $\mathbf{x}$ & $\mathbf{x}$ & $\mathbf{x}$ & $\mathbf{x}$ & $\mathbf{x}$ & $\mathbf{x}$ & $\mathbf{x}$ & $\mathbf{x}$ & $\mathrm{x}$ & $\mathbf{x}$ & $\mathbf{x}$ & $\mathbf{x}$ & $\mathbf{x}$ & $\mathbf{x}$ & $\mathbf{x}$ & $\mathbf{x}$ & $\mathbf{x}$ \\
\hline 2002 & $\mathbf{x}$ & $\mathrm{x}$ & $\mathbf{x}$ & $\mathrm{x}$ & $\mathbf{x}$ & $\mathbf{x}$ & $\mathrm{x}$ & $\mathbf{x}$ & $\mathbf{x}$ & $\mathbf{x}$ & $\mathbf{x}$ & $\mathbf{x}$ & $\mathbf{x}$ & $\mathrm{x}$ & $\mathrm{x}$ & $\mathrm{x}$ & $\mathbf{x}$ & $\mathbf{x}$ & $\mathbf{x}$ & $\mathrm{x}$ & $\mathrm{x}$ & $\mathbf{x}$ & $\mathbf{x}$ & $\mathbf{x}$ & $\mathbf{x}$ & $\mathbf{x}$ & $\mathrm{x}$ & $\mathbf{x}$ \\
\hline 2003 & $\mathbf{x}$ & $\mathrm{x}$ & $\mathrm{x}$ & $\mathrm{x}$ & $\mathrm{x}$ & $\mathrm{x}$ & $\mathrm{x}$ & $\mathbf{x}$ & $\mathbf{x}$ & $\mathbf{x}$ & $\mathbf{x}$ & $\mathbf{x}$ & $\mathbf{x}$ & $\mathrm{x}$ & $\mathrm{x}$ & $\mathrm{x}$ & $\mathbf{x}$ & $\mathbf{x}$ & $\mathbf{x}$ & $x$ & $\mathrm{x}$ & $x$ & $\mathbf{x}$ & $\mathrm{x}$ & $\mathbf{x}$ & $\mathbf{x}$ & $\mathrm{x}$ & $\mathrm{x}$ \\
\hline 2004 & $\mathbf{x}$ & $\mathbf{x}$ & $\mathrm{x}$ & $\mathrm{x}$ & $\mathbf{x}$ & $\mathrm{x}$ & $\mathrm{x}$ & $\mathbf{x}$ & $\mathbf{x}$ & $\mathbf{x}$ & $\mathrm{x}$ & $\mathrm{x}$ & $\mathrm{x}$ & $\mathrm{x}$ & $\mathrm{x}$ & $\mathrm{x}$ & $\mathbf{x}$ & $\mathrm{x}$ & $\mathrm{x}$ & $\mathrm{x}$ & $\mathrm{x}$ & $\mathrm{x}$ & $\mathrm{x}$ & $\mathrm{x}$ & $\mathrm{x}$ & $\mathbf{x}$ & $\mathrm{x}$ & $\mathrm{x}$ \\
\hline 2005 & $\mathbf{x}$ & $\mathbf{x}$ & $\mathbf{x}$ & $\mathbf{x}$ & $\mathbf{x}$ & $\mathrm{x}$ & $\mathrm{x}$ & $\mathbf{x}$ & $\mathbf{x}$ & $\mathbf{x}$ & $\mathbf{x}$ & $\mathbf{x}$ & $\mathbf{x}$ & $\mathbf{x}$ & $\mathrm{x}$ & $\mathrm{x}$ & $\mathbf{x}$ & $\mathrm{x}$ & $\mathbf{x}$ & $\mathrm{x}$ & $\mathbf{x}$ & $\mathrm{x}$ & $\mathbf{x}$ & $\mathrm{x}$ & $\mathrm{x}$ & $\mathbf{x}$ & $\mathrm{x}$ & $\mathbf{x}$ \\
\hline 2006 & $\mathbf{x}$ & $\mathbf{x}$ & $\mathbf{x}$ & $\mathbf{x}$ & $\mathbf{x}$ & $\mathrm{x}$ & $\mathbf{x}$ & $\mathbf{x}$ & $\mathbf{x}$ & $\mathbf{x}$ & $\mathbf{x}$ & $\mathbf{x}$ & $\mathbf{x}$ & $\mathbf{x}$ & $\mathbf{x}$ & $\mathrm{x}$ & $\mathbf{x}$ & $\mathbf{x}$ & $\mathbf{x}$ & $\mathbf{x}$ & $\mathbf{x}$ & $\mathbf{x}$ & $\mathrm{x}$ & $\mathbf{x}$ & $\mathbf{x}$ & $\mathbf{x}$ & $\mathrm{x}$ & $\mathbf{x}$ \\
\hline 2007 & $\mathrm{x}$ & $\mathrm{x}$ & $\mathbf{x}$ & $\mathrm{x}$ & $\mathbf{x}$ & $\mathrm{x}$ & $\mathrm{x}$ & $\mathbf{x}$ & $\mathbf{x}$ & $\mathbf{x}$ & $\mathbf{x}$ & $\mathbf{x}$ & $\mathrm{x}$ & $\mathbf{x}$ & $\mathrm{x}$ & $\mathrm{x}$ & $\mathbf{x}$ & $\mathbf{x}$ & $\mathbf{x}$ & $\mathrm{x}$ & $\mathrm{x}$ & $\mathrm{x}$ & $\mathrm{x}$ & $\mathrm{x}$ & $\mathbf{x}$ & $\mathbf{x}$ & $\mathrm{x}$ & $\mathbf{x}$ \\
\hline 2008 & $\mathbf{x}$ & $\mathbf{x}$ & $\mathrm{x}$ & $\mathrm{x}$ & $\mathbf{x}$ & $\mathrm{x}$ & $\mathrm{x}$ & $\mathbf{x}$ & $\mathbf{x}$ & $\mathrm{x}$ & $\mathbf{x}$ & $\mathbf{x}$ & $\mathbf{x}$ & $\mathbf{x}$ & $\mathrm{x}$ & $\mathrm{x}$ & $\mathbf{x}$ & $\mathrm{x}$ & $\mathbf{x}$ & $\mathrm{x}$ & $\mathrm{x}$ & $\mathrm{x}$ & $\mathrm{x}$ & $\mathbf{x}$ & $\mathbf{x}$ & $\mathbf{x}$ & $\mathrm{x}$ & $\mathbf{x}$ \\
\hline 2009 & $\mathbf{x}$ & $\mathbf{x}$ & $\mathbf{x}$ & $\mathbf{x}$ & $\mathbf{x}$ & $\mathrm{x}$ & $\mathbf{x}$ & $\mathbf{x}$ & $\mathbf{x}$ & $\mathbf{x}$ & $\mathbf{x}$ & $\mathbf{x}$ & $\mathbf{x}$ & $\mathbf{x}$ & $\mathrm{x}$ & $\mathrm{x}$ & $\mathbf{x}$ & $\mathrm{x}$ & $\mathbf{x}$ & $\mathbf{x}$ & $\mathbf{x}$ & $\mathrm{x}$ & $\mathrm{x}$ & $\mathbf{x}$ & $\mathbf{x}$ & $\mathbf{x}$ & $\mathrm{x}$ & $\mathbf{x}$ \\
\hline 2010 & $\mathbf{x}$ & $\mathrm{x}$ & $\mathbf{x}$ & $\mathrm{x}$ & $\mathbf{x}$ & $\mathrm{x}$ & $\mathrm{x}$ & $\mathbf{x}$ & $\mathbf{x}$ & $\mathbf{x}$ & $\mathrm{x}$ & $\mathbf{x}$ & $\mathbf{x}$ & $\mathbf{x}$ & $\mathrm{x}$ & $\mathbf{x}$ & $\mathbf{x}$ & $\mathbf{x}$ & $\mathbf{x}$ & $\mathbf{x}$ & $\mathrm{x}$ & $\mathrm{x}$ & $\mathbf{x}$ & $\mathbf{x}$ & $\mathrm{x}$ & $\mathbf{x}$ & $\mathrm{x}$ & $\mathrm{x}$ \\
\hline 011 & $\mathbf{x}$ & $\mathbf{x}$ & $\mathbf{x}$ & $\mathbf{x}$ & $\mathbf{x}$ & $\mathbf{x}$ & $\mathrm{x}$ & $\mathbf{x}$ & $\mathbf{x}$ & $\mathbf{x}$ & $\mathbf{x}$ & $\mathbf{x}$ & $\mathbf{x}$ & $\mathbf{x}$ & $\mathbf{x}$ & $\mathrm{x}$ & $\mathbf{x}$ & $\mathrm{x}$ & $\mathbf{x}$ & $\mathbf{x}$ & $\mathbf{x}$ & $\mathbf{x}$ & $\mathrm{x}$ & $\mathbf{x}$ & $\mathbf{x}$ & $\mathbf{x}$ & $\mathrm{x}$ & $\mathbf{x}$ \\
\hline 2012 & $\mathbf{x}$ & $\mathbf{x}$ & $\mathbf{x}$ & $\mathbf{x}$ & $\mathbf{x}$ & $\mathrm{x}$ & $\mathbf{x}$ & $\mathbf{x}$ & $\mathbf{x}$ & $\mathbf{x}$ & $\mathbf{x}$ & $\mathbf{x}$ & $\mathbf{x}$ & $\mathbf{x}$ & $\mathbf{x}$ & $\mathrm{x}$ & $\mathbf{x}$ & $\mathrm{x}$ & $\mathbf{x}$ & $\mathrm{x}$ & $\mathbf{x}$ & $\mathrm{x}$ & $\mathbf{x}$ & $\mathbf{x}$ & $\mathbf{x}$ & $\mathbf{x}$ & $\mathrm{x}$ & $\mathbf{x}$ \\
\hline 013 & $\mathrm{x}$ & $\mathbf{x}$ & $\mathrm{x}$ & $\mathrm{x}$ & $\mathbf{x}$ & $\mathrm{x}$ & $\mathbf{x}$ & $\mathbf{x}$ & $\mathbf{x}$ & $\mathbf{x}$ & $\mathbf{x}$ & $\mathbf{x}$ & $\mathbf{x}$ & $\mathbf{x}$ & $\mathbf{x}$ & $\mathbf{x}$ & $\mathbf{x}$ & $\mathrm{x}$ & $\mathbf{x}$ & $\mathrm{x}$ & $\mathrm{x}$ & $\mathbf{x}$ & $\mathrm{x}$ & $\mathbf{x}$ & $\mathrm{x}$ & $\mathbf{x}$ & $\mathrm{x}$ & $\mathbf{x}$ \\
\hline 2014 & $x$ & $\mathbf{x}$ & $\mathbf{x}$ & $\mathrm{x}$ & $\mathbf{x}$ & $\mathrm{x}$ & $\mathbf{x}$ & $\mathbf{x}$ & $\mathbf{x}$ & $\mathbf{x}$ & $\mathbf{x}$ & $\mathbf{x}$ & $\mathbf{x}$ & $\mathbf{x}$ & $\mathbf{x}$ & $\mathrm{x}$ & $\mathbf{x}$ & $\mathbf{x}$ & $\mathbf{x}$ & $\mathbf{x}$ & $\mathbf{x}$ & $\mathbf{x}$ & $\mathbf{x}$ & $\mathbf{x}$ & $\mathbf{x}$ & $\mathbf{x}$ & $\mathrm{x}$ & $\mathbf{x}$ \\
\hline 2013 & $\mathbf{x}$ & $\mathbf{x}$ & $\mathbf{x}$ & $\mathbf{x}$ & $\mathbf{x}$ & $\mathrm{x}$ & $\mathrm{x}$ & $\mathbf{x}$ & $\mathrm{x}$ & $\mathbf{x}$ & $\mathbf{x}$ & $\mathbf{x}$ & $\mathbf{x}$ & $\mathbf{x}$ & $\mathbf{x}$ & $\mathrm{x}$ & $\mathbf{x}$ & $\mathrm{x}$ & $\mathbf{x}$ & $\mathbf{x}$ & $\mathbf{x}$ & $\mathbf{x}$ & $\mathbf{x}$ & $\mathbf{x}$ & $\mathbf{x}$ & $\mathbf{x}$ & $\mathrm{x}$ & $\mathrm{x}$ \\
\hline 2016 & $\mathbf{x}$ & $\mathbf{x}$ & $\mathrm{x}$ & $\mathbf{x}$ & $\mathbf{x}$ & $\mathbf{x}$ & $\mathbf{x}$ & $\mathbf{x}$ & $\mathbf{x}$ & $\mathbf{x}$ & $\mathbf{x}$ & $\mathbf{x}$ & $\mathbf{x}$ & $\mathbf{x}$ & $\mathbf{x}$ & $\mathbf{x}$ & $\mathrm{x}$ & $\mathbf{x}$ & $\mathbf{x}$ & $\mathbf{x}$ & $\mathbf{x}$ & $\mathbf{x}$ & $\mathrm{x}$ & $\mathrm{x}$ & $\mathbf{x}$ & $\mathbf{x}$ & $\mathbf{x}$ & $\mathbf{x}$ \\
\hline
\end{tabular}

Using station data, it is found difficult and insufficient to assess the impact of climate variability on malaria distribution for woreda level. Therefore, high resolution data used to study the condition for the entire woreda based on the ensemble of gridded data cell available.

Thus, using high resolution gridded data, in the next sub sections the climate malaria suitability is studied and the results are discussed, for Debark district with 24 grid areas near to the station.

\subsection{Climate Impact on Malaria using Gridded Data for Debark District}

The following table presents six selected grid cells with their georeferenced locations, altitudes and distance and direction of meteorological station that found at Debark town. Each grid area represents four by four $\mathrm{km}$ area coverage which is equal to $16 \mathrm{~km} 2$. Initially, 24 grid cells which have $384 \mathrm{~km} 2$ in area coverage, debark station location being at the center. This area had a distance of $12.0 \mathrm{~km}$ East and West of Debark station and $8.0 \mathrm{~km}$ North and South of the station, on average. Out of 24 grid locations, the result of assessment showed that only on the six locations given listed below was the climate driven malaria transmission have been found to exist (table 5).

Table5. Georeferenced location of grid cells along with altitude, distance and direction

\begin{tabular}{|l|l|l|l|l|l|}
\hline Latitude & $\begin{array}{l}\text { Longitud } \\
\text { e }\end{array}$ & $\begin{array}{l}\text { Altitude } \\
(\mathrm{m})\end{array}$ & $\begin{array}{l}\text { Lat., Long. \& Altitude (m) } \\
\text { of Debark Station }\end{array}$ & $\begin{array}{l}\text { Distance from } \\
\text { Debark } \\
\text { Station(km) }\end{array}$ & $\begin{array}{l}\text { Direction } \\
\text { from Debark } \\
\text { Station }\end{array}$ \\
\hline 13.18175 & 37.81875 & 1941.0 & $13.14213,37.8979,2836$ & 9.6 & N-W \\
\hline 13.21875 & 37.81875 & 2175.8 & $13.14213,37.8979,2836$ & 12.1 & N-W \\
\hline 13.21875 & 37.85625 & 2143.5 & $13.14213,37.8979,2836$ & 9.6 & N-W \\
\hline 13.21875 & 37.89375 & 2069.2 & $13.14213,37.8979,2836$ & 8.5 & N-W \\
\hline 13.21875 & 37.93125 & 1922.8 & $13.14213,37.8979,2836$ & 9.3 & N-E \\
\hline 13.21875 & 37.96875 & 2803.4 & $13.14213,37.8979,2836$ & 11.5 & N-E \\
\hline
\end{tabular}




\subsection{Malaria Climatic Suitability for 13.21875 Latitude and 37.81875 Longitude Location}

We here provide, as example, one of the six places the Climatic Suitability for malaria transmission is satisfied, as shown on the following table. The climate variables which are determinant for malaria transmission are brought with the necessary threshold values. These are monthly precipitation cumulative (with blue color), mean monthly temperature threshold 18-32 oc (with red color) and relative humidity greater than $60 \%$.

The grid cell location represented with 13.21875 latitude and 37.81875 longitude is found $12.1 \mathrm{~km}$ away from Debark weather station in North West direction at altitude of $2175.8 \mathrm{~m}$. The elevation is lower than Debark weather station which is equal to $2836 \mathrm{~m}$. Regarding to climate malaria relation, this location also revealed a better malaria distribution as compared to the location round the Debark weather station. In this case, the month of June is found to be a major malaria transmission season stating from 1998 and onwards. This result is due to an increasing in precipitation on JJAS season, (sea fig. 4). While the month of May, July and August favo-red a positive impact on malaria distribute as a result of increasing temperature trend (fig 4.1.2.a-e) and prolonged rainy season in 2016.

Table6. Malaria Climatic Suitability for 13.21875 latitude and 37.81875 longitude location

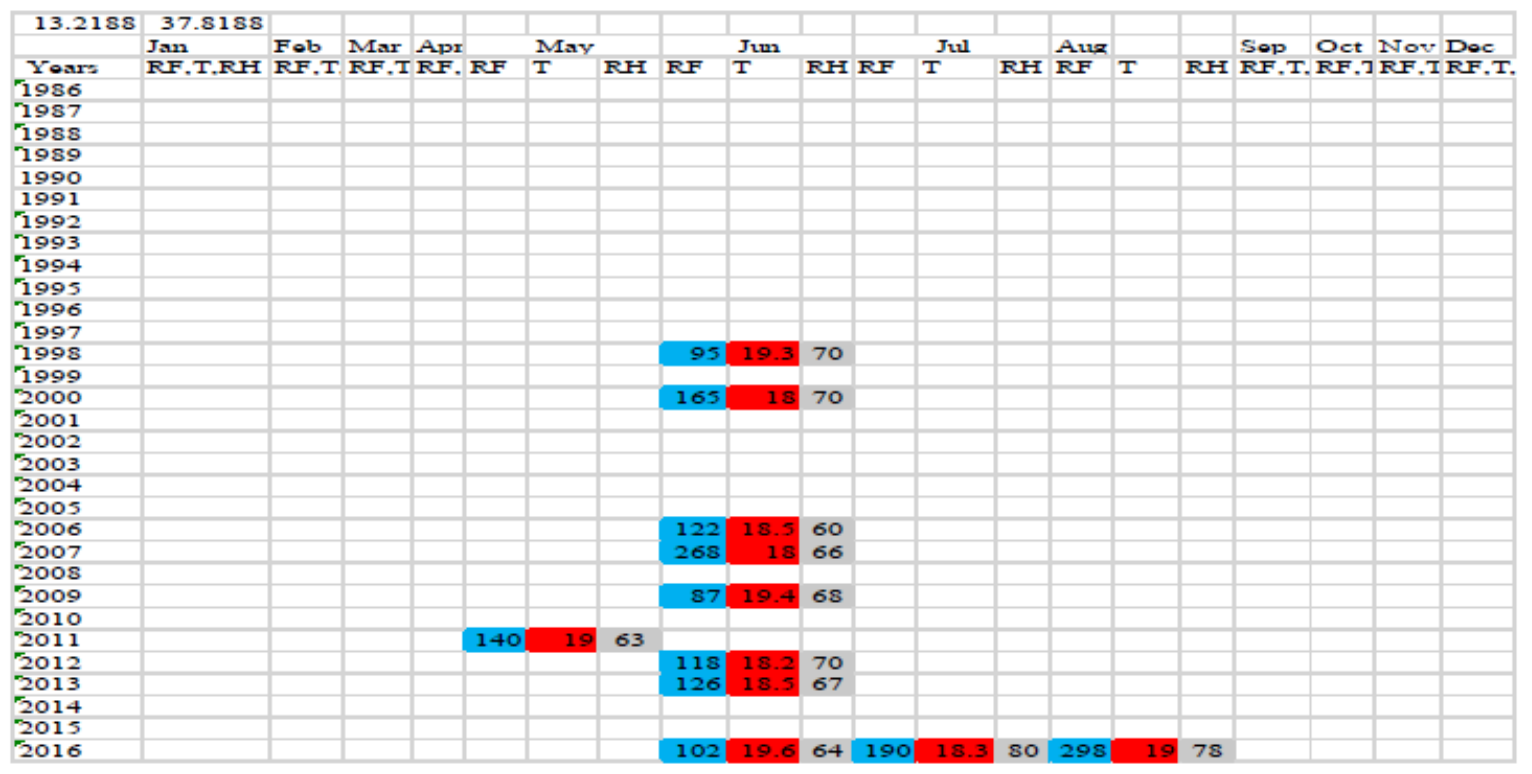

The rest of the location which exhibited malaria transmission are summarized as follows.

21 number of months were found to favor for malaria transmission at $1941.0 \mathrm{~m}$ height; 11 number of months at $2175.8 \mathrm{~m}$ height; While, 7 months at $2069.2 \mathrm{~m}$ and Only one month at $2803.8 \mathrm{~m}$ height. On all places, the number of months increased gradually. For prolonged number of months, the climate was favorable on the recent years $(2015,2016)$ on all the six locations. Except for the location with height $2069.2 \mathrm{~m}$, in general, the number of months favorable for malaria decrease with altitude. The reason for this exceptional case was that the place $(2069 \mathrm{~m}, \mathrm{~N}-\mathrm{W}$ of Debark station) was found to be 'rain shadow area', with smallest RF amount compared to other locations with similar topographical height over the surroundings.

The ENACTS data set shows the details of malaria transmission since it is a high-resolution data that can depict the actual fact happened on the ground. So, we could observe that malaria existed at different altitudes (1922.8 to $2803.4 \mathrm{~m}$ ) and very near distance from Debark town (9.6 to12.1 km) where the weather station is located, $2836.0 \mathrm{~m}$ altitude. To this analogue, a study done before by International travel advisories (IAMAT, 2013) specify that Addis Ababa is malaria free. However, malaria cases are diagnosed within the city limits as a result of infections acquired outside the city or within its growing periphery Woyessa \& Ali, 2003; Woyessa et al. 2004. In similar manner, the result obtained on some locations showed that the climate suitability which was experienced in recent years (2015) is the cause for the detection of malaria near to Debark or with its periphery area, just at 11.5 $\mathrm{km}$ distant from the 'center' (referring to weather station location) and at approximately $2803.4 \mathrm{~m}$ altitude above mean sea level. 
With these analyses, our result displayed the malaria transmission in a better manner compared to the result obtained by MARA13 (Source: Ethiopia-Epi-report-020520) malaria projection model forecasted for the recent year 2015, (see the map under Annex C.2). The model used the same logic as we used in malaria climate suitability in this paper. The product of the model, issued for the year 2015 , showed that the malaria incidence elevation was expected be $2,500 \mathrm{~m}$, where areas above this height are supposed to be malaria free regions. However, in our assessment result we have seen that the climate became conducive for malaria incidence just at elevation of $2803.8 \mathrm{~m}$, recently (on 2015 , table 5.2.2.7).

\section{Climate Variability Versus Malaria Expectation Pattern}

The following results showed malaria expectation pattern in relation to the variability of climate parameters time series over Combolcha and Debark Woredas.

\subsection{Climate Variability Versus Malaria Expectation Pattern Over Combolcha}

The following results showed malaria expectation pattern in relation to the variability of climate parameters time series over Combolcha.

Clearly, a slight decreasing trend in malaria occurrence is observed similar to the precipitation trend regardless of the increase in temperature, during 1986-2016 over Combolcha. In similar speaking, on FMAM and JJAS seasons there were a significant decrease in precipitation, from 2001 up to 2008. This condition collapsed malaria transmission on FMAM during the indicated years. In the next two years, the temperature increases along with the increase in precipitation allow the disease reemerging. Again, the increase and decrease of temperature and precipitation directly affects malaria transmission in positive and negative face during the years 2009-2011 and 2011-2014, respectively. In addition, the increase of malaria transmission in 1988,1989, 1993,1994 and 1998 is due to the effect of the temperature and precipitation increase; the reverse is true on the rest of the years.

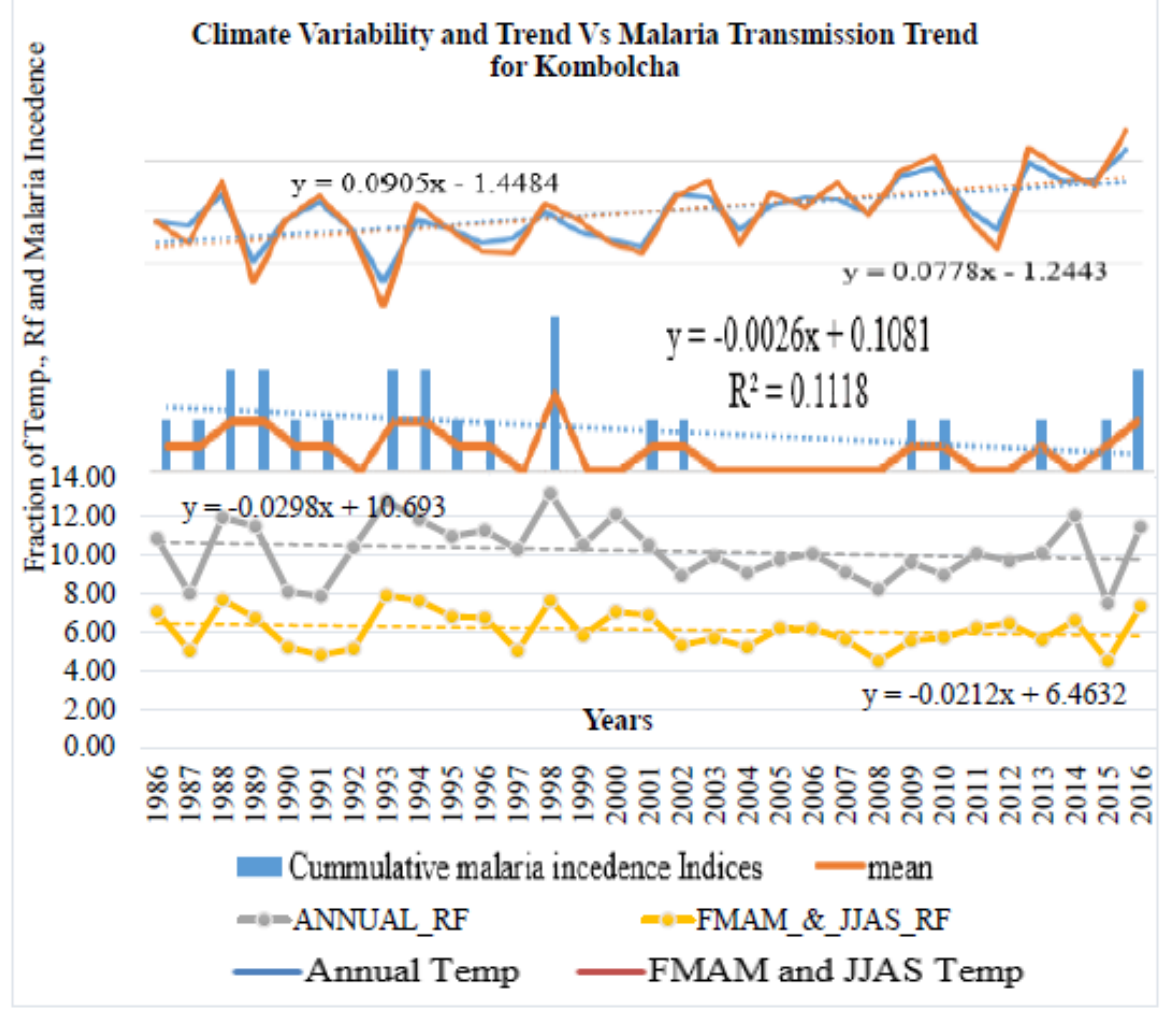

Figure11. Trend and variability of precipitation on FMAM_JJAS and ANNUAL, Malaria Expectation Tend and Time series for Kombolcha Woreda and Trend variability of Temperature on FMAM_JJAS and ANNUAL

In general, the increase and decrease of the malaria transmission was the direct result of the increasing and decreasing periods in precipitation and rain fall. From table 4.3.1 one can see that RF strongly correlated on FMAM and JJAS with 0.64 and 0.49 than the temperature, over Combolcha woreda. The lower temperature correlation with negative sign (-0.14 and -0.29) indicates that the influence of 
increasing or decreasing temperature in reducing or advancing malaria transmission was less significant since the temperature measure could already exceed the threshold on FMAM and JJAS over Combolcha. Again, this indirectly tell us that the precipitation was primarily responsible for malaria transmission-fluctuation than the temperature. But, when we compare the two seasons independently an increase in temperature on JJAS is relatively significant to favor malaria transmission than on FMAM. The same is true for the decreasing of malaria. In other words, the variability of temperature is slightly correlated to malaria transmission-fluctuation on JJAS than FMAM, relatively.

Table7. Coefficient of correlation that shows the malaria occurrence fluctuation and trend in response to climate trend and variability of weather parameters on seasonal time scale.

\begin{tabular}{|c|c|c|c|c|c|}
\hline \multirow{3}{*}{ Station } & \multicolumn{4}{|l|}{ Corr. Coeff. (r) between Variability of Climate and Malaria Occurrence Trend } \\
\hline \multirow{3}{*}{ Debark } & \multicolumn{2}{|c|}{ Climate Variables } & \multicolumn{4}{|c|}{ Seasons } \\
\cline { 2 - 6 } & & Annual & JJAS & FMAM & ONDJ \\
\cline { 2 - 6 } & RF & 0.12 & 0.01 & 0.37 & Null \\
\cline { 2 - 6 } & Temp. & 0.45 & 0.53 & 0.13 & Null \\
\hline Kombolcha & RF & 0.43 & 0.49 & 0.64 & -0.199 \\
& Temp. & -0.09 & -0.14 & -0.29 & -0.083 \\
\cline { 2 - 6 } & & & & & \\
\hline
\end{tabular}

The above table reminds us that the change and temporal variability in malaria transmission is related to the change in temperature and rain fall performance. The correlation value with +1 indicates a strong direct relation, -1 a strong relation on the contrary, near to Zero magnitude indicates slight relation and 'Null' is insignificant (very poor relation).

\subsection{Climate Variability Versus Malaria Expectation Pattern Over Debark}

The following results shows malaria expectation pattern in relation to the variability of climate parameters time series over Debark.

Unlike to Combolcha woreda, the temperature plays the principal role than the precipitation in controlling the malaria transmission variability and trends, over Debark woreda. As shown on the above graph, the malaria occurrence had strong increasing trend just as the temperature trend pattern. However, the precipitation also had a moderate positive relation and slight increasing trend on FMAM; and a slight

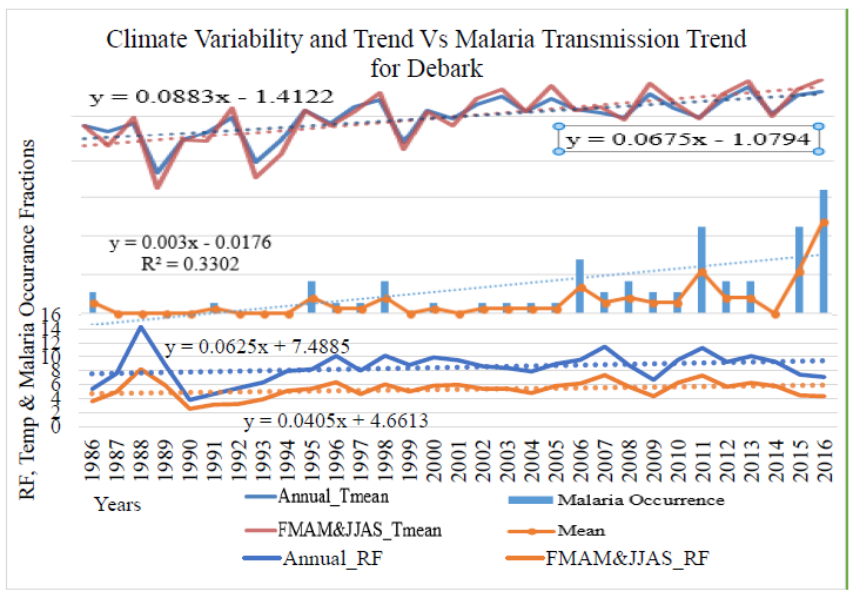

Figure12. Trend and variability of precipitation on FMAM_JJAS and ANNUAL, Malaria Expectation Tend and Time series for Debark Woreda and Trend variability of Temperature on FMAM_JJAS and ANNUAL 
correlation and increasing trend on JJAS were identified. In general, over this woreda the temperature is strongly correlated $(0.53$, on JJAS) and the precipitation is correlated moderately $(0.37$, on FMAM) in response to malaria occurrence and variability.

\section{Projection of Climate ImpaCt On Malaria Transmission}

In this section, first we see the climate projection changes for temperature and precipitation over Great Horn of Africa, extracted from IGAD Climate Prediction and Application Center (ICPAC) for our study areas. Apart from this we also considered the rate of temperature increase with elevation, based on the results obtained from recently published paper, B. Lyon et al., 15 June, 2017. prospect on the future, over our study areas, based on the climate suitability in view of the future climate scenarios.

\subsection{Projection of Climate for Different Scenarios and Different Altitudes}

The projection of climate change was performed with rough estimate as it was extracted from the secondary data source like ICPAC (IGAD CLIMATE PREDICTION AND APPLICATION CENTER) publications and website and from results of different published papers.

\subsubsection{Projection Of Climate For Different Scenarios As Extracted From ICPAC}

Projection of Climate for different Scenarios were extracted from ICPAC with different regional climate models along with their ensemble average. For both Combolcha and Debark woredas, the mean temperature and rainfall were projected for the scenarios like: 2020, 2030 and 2050. The regional climate models used for this projection were RCM2.6, RCM4.5, and RCM8.5. Finally, for our purpose, the ensemble average was taken which is supposed to minimize an error (Annex B). The same was done for relative humidity qualitatively based on the temperature and precipitation changes expected in future (refer to section 2.1.4 last paragraph).

\subsubsection{Elevation-Dependent Temperature Projection on Temporal Base}

Here, elevation dependent temperature projection is done for Debark district. This is performed depending on the result obtained from B. Lyon et al., 15 June, 2017. This result brought us with the secondary data (Annex C) which infer the temperature rate with respect to elevation. According to this outcome, for a fixed temperature value (18 oc) a 31.2meter increase in elevation per decade (10 years) was observed. Based on this, we deduced and extrapolated the height, on future scenarios, over where this fixed temperature value potentially reach at (table 8). In case of Combolcha woreda, the elevation dependent temperature forecast did not give a sense since the elevation is relatively low and the temperature value under consideration (18 oc) is already exhibited on previous period (1986-2016) over this altitude. Therefore, we perform this temperature estimate only for Debark.

Table8. Elevation dependent temperature projection over Debark District

\begin{tabular}{|l|l|l|l|}
\hline \multirow{3}{*}{ Station } & Climate Periods & \multicolumn{2}{l|}{ Elevation Dependent Temperature Projection } \\
\cline { 3 - 4 } & & Altitude & Temperature \\
\hline \multirow{5}{*}{ Debark } & Previous term (1986-2016) & 2803.8 meter & 18 degree centigrade \\
\cline { 2 - 4 } & Current mid-term (2020) & 2836.3 meter & 18 degree centigrade \\
\cline { 2 - 4 } & Near-term (2030) & 2867.6 meter & 18 degree centigrade \\
\cline { 2 - 4 } & middle-term (2050) & 2930.0 meter & 18 degree centigrade \\
\hline
\end{tabular}

The fixed, $18.0^{\circ} \mathrm{c}$, temperature increases with $31.2 \mathrm{~m}$ height per each decade. Under section climate assessment section, the mean temperature was detected to reach $2803.8 \mathrm{~m}$ with magnitude greater than $18.0 \mathrm{oc}$. Thus, using this result together with the following evidences the future prospect of malaria transmission was introduced in the next paragraph as follows. 
On the upcoming climate periods the temperature just reach at the corresponding heights shown in the table 8. Thus, starting from the period 2020 the temperature becomes suitable for malaria transmission just at elevation of Debark weather station which is about 2836.0-meter-high above the ground. Again, under climate assessment section the precipitation and relative humidity measures already full fill the favorable condition for malaria transmission for several months, most frequently on June, July, August and September. So, with the justification of these data (table 8, and climate assessment) there will be incidence of malaria starting from 2020 and afterwards, over such high ground, in Debark woreda. More probably, the months that will be experienced by malaria incidence are anticipated to be June, May and July, in order, since these months contribute to the principal rain fall amount with little variability, even under future climate change in precipitation. Again, the temperature is expected to favor malaria occurrence due to the change in air temperature in future on the aforementioned months (see table 9).

\subsection{Future Prospect of Malaria Transmission}

The introduction of the future prospect of malaria distribution discussed in the previous section was based on the data extracted from elevation dependent temperature projection. In addition to the above introduction, in this section again, a tabular demonstration is conducted below to display the future malaria transmission prospect based on another data source generated through the task of future climate change projection. And, this data was gained by extracting from ICPAC climate information sources. Then, similarities and differences of the results obtained by these two approaches about malaria distribution prospect are discussed next under this section.

\subsubsection{Future Prospect of Malaria Transmission Over Debark}

Table9. Future prospect in Malaria Transmission over Debark Woreda

\begin{tabular}{|c|c|c|c|c|c|c|c|c|c|c|c|c|}
\hline Station & \multicolumn{12}{|c|}{ Debark (Altitude $=2836.0 \mathrm{~m})$} \\
\hline Months & Jan & Feb & Mar & Apr & May & Jun & Jul & Ang & Sep & Oct & Nov & Dec \\
\hline T_Forcast_2020 & 16.4 & 18.2 & 19.1 & 19.6 & 19.3 & 18.9 & 17.4 & 17.4 & 17.7 & 17.3 & 16.9 & 17.0 \\
\hline T_Forcast_2030 & 15.6 & 17.2 & 18.1 & 18.6 & 18.3 & 18.2 & 15.7 & 15.7 & 16.0 & 15.6 & 15.2 & 15.3 \\
\hline T_Forcast_2050 & 15.9 & 18.3 & 19.3 & 19.8 & 19.4 & 18.5 & 18.1 & 17.6 & 17.3 & 15.9 & 15.5 & 15.6 \\
\hline RF_Forcast_2020 & 0.5 & 1.5 & 20.0 & 32.6 & 110.2 & 169.6 & 157.3 & 168.6 & 116.1 & 66.6 & 3.6 & 0.5 \\
\hline RF_Forcast_2030 & 0.7 & 2.0 & 21.1 & 33.7 & 111.3 & 170.7 & 158.4 & 169.7 & 117.2 & 67.7 & 4.7 & 0.7 \\
\hline RF_Forcast_2050 & 1.0 & 5.5 & 14.9 & 27.5 & 105.1 & 164.5 & 152.2 & 163.5 & 111.0 & 77.3 & 14.3 & 10.3 \\
\hline RH_Average & 41.0 & 40.8 & 42.5 & 48.6 & 54.0 & 73.7 & 86.7 & 88.3 & 79.4 & 62.6 & 56.5 & 48.9 \\
\hline RH_Average & 50.7 & 44.9 & 46.8 & 53.4 & 61.0 & 73.7 & 86.7 & 88.3 & 79.4 & 77.5 & 69.9 & 60.6 \\
\hline \multirow[t]{3}{*}{$\mathrm{RH}$ _Average } & 50.7 & 49.4 & 51.5 & 60.0 & 66.0 & 60.3 & 86.7 & 92.7 & 83.3 & 77.5 & 69.9 & 60.6 \\
\hline & \multicolumn{12}{|c|}{ Favorable months for malaria under future prospect of climate change scenarios } \\
\hline & Jan & Feb & Mar & Apr & May & June & July & Aug & Sep & Oct & Nov & Dec \\
\hline \multirow{3}{*}{ Previous term(1986-2016 } & Nil & Nil & Nil & Nil & $\mathrm{x}$ & $\mathrm{x}$ & $\mathrm{x}$ & Nil & Nil & Nil & Nil & Nil \\
\hline & Nil & Nil & Nil & Nil & $\mathrm{x}$ & $\mathrm{x}$ & $\mathrm{x}$ & Nil & Nil & Nil & Nil & Nil \\
\hline & Nil & Nil & Nil & Nil & $\mathrm{x}$ & $\mathrm{x}$ & $\mathrm{x}$ & Nil & Nil & Nil & Nil & Nil \\
\hline \multirow{3}{*}{ Current mid-term(2020) } & Nil & $\mathrm{Nil}$ & Nil & Nil & $\mathrm{x}$ & 18.9 & $\mathrm{x}$ & Nil & Nil & Nil & Nil & Nil \\
\hline & $\mathrm{Nil}$ & Nil & $\mathrm{Nil}$ & Nil & $\mathrm{x}$ & 169.6 & $\mathrm{x}$ & Nil & Nil & Nil & Nil & Nil \\
\hline & Nil & Nil & $\mathrm{Nil}$ & Nil & $\mathrm{x}$ & 73.6645 & $\mathrm{x}$ & Nil & Nil & Nil & Nil & Nil \\
\hline \multirow{3}{*}{ Near-term(2030) } & $\mathrm{Nil}$ & $\mathrm{Nil}$ & Nil & Nil & 18.2 & 18.2 & $\mathrm{x}$ & Nil & Nil & Nil & Nil & Nil \\
\hline & $\mathrm{Nil}$ & $\mathrm{Nil}$ & Nil & Nil & 111.3 & 170.7 & $\mathrm{x}$ & Nil & Nil & Nil & Nil & Nil \\
\hline & Nil & Nil & Nil & Nil & 61.0 & 73.7 & $\mathrm{x}$ & Nil & Nil & Nil & Nil & Nil \\
\hline \multirow{3}{*}{ middle-term(2050) } & $\mathrm{Nil}$ & Nil & Nil & Nil & 18.5 & 18.5 & 18.1 & Nil & Nil & Nil & Nil & Nil \\
\hline & Nil & Nil & Nil & Nil & 105.1 & 164.5 & 152.2 & Nil & Nil & Nil & Nil & Nil \\
\hline & $\mathrm{Nil}$ & Nil & Nil & Nil & 66.0 & 70.3 & 86.7 & Nil & Nil & Nil & Nil & Nil \\
\hline
\end{tabular}

The above table 9 denotes Malaria Transmission Prospect over Debark Station; ' $x$ ' symbol indicates that there is no observation of malaria transmission; the symbol 'Nil' represents there was no expectation of a suitable condition for malaria occurrence on the previous period (1986-2016) and no change anticipated in the future; and the table cells with colors and the respective temperature, precipitation and $\mathrm{RH}$ values represents the future expectation of malaria incidence event along with the corresponding starting climate period and months.

Thus, as one can observe from the above table that in consequence of the climate change the temperature becomes suitable for malaria transmission on months like February to July. Regarding to 
the precipitation the monthly amount is greater than $80 \mathrm{~mm}$ during the months of May to September, regardless of the climate change effect. Therefore, the transmission of malaria is anticipated to incident on the month of June starting from the near future (2020), over such high altitude where there was no a case before. This result was similar to the one described in the previous section, that tells us about the starting period (2020) of the malaria incidence in Debark woreda at elevation of 2836.0 meter, due to elevation dependent temperature increase.

Next, the number of months favoring for malaria transmission increased by one month (May) just on the period 2030. Once again, the increase of temperature along with the other climate variables let the number of months to increase again by one month (July) on the period 2050. On the other hand, the rest of the months remained unfavorable, for future, for malaria transmission as before. In general, the future climate condition will be suitable for malaria to inhabit over higher and higher elevation in Debark woreda with increased number of months, gradually.

\subsubsection{Future Prospect of Malaria Transmission Over Combolcha}

Similar to Debark woreda, tabular demonstration of future malaria assessment was carried out based on climate factors, as provided in the next table. For the whole climate scenarios (2020, 2030 and 2050) the temperature was found to have a positive impact on future malaria transmission. Whereas, the precipitation is observed in decreasing manner decade to decade in the future on FMAM (Belg season); and it increases on the Bega season (ONDJ), extending number of months, decade to decade.

As one can see from the table provided next, earlier to 2016 there were malaria transmission seasons experienced following the rainy seasons (FMAM and JJAS). The most common months associated with malaria occurrence were March, April, August and September; rarely in February, very rarely in July and October months, before the year 2016. And, the months denoted by 'Nil' are those on which the climate totally did not seen to encourage for malaria transmission.

Table10. Future prospect in Malaria Transmission over Combolcha Woreda

\begin{tabular}{|c|c|c|c|c|c|c|c|c|c|c|c|c|}
\hline Station & \multicolumn{12}{|c|}{ Combolcha } \\
\hline Months & Jan & Feb & Mar & Apr & May & Jun & Jul & Aug & Sep & Oct & Nov & Dec \\
\hline T_Forcast_2020 & 19.7 & 20.8 & 22.1 & 22.8 & 23.7 & 25.0 & 23.9 & 23.1 & 22.3 & 20.5 & 19.3 & 18.9 \\
\hline T_Forcast_2030 & 19.4 & 20.8 & 22.1 & 22.8 & 23.7 & 24.9 & 23.8 & 23.0 & 22.2 & 20.2 & 19.0 & 18.6 \\
\hline T Forcast 2050 & 21.7 & 23.0 & 24.3 & 25.0 & 25.9 & 26.9 & 25.8 & 25.0 & 24.2 & 22.5 & 21.3 & 20.9 \\
\hline RF Forcast 2020 & 27.9 & 9.9 & 49.7 & 80.3 & 43.1 & 29.4 & 271.9 & 262.1 & 104.4 & 49.6 & 23.3 & 22.0 \\
\hline RF Forcast 2030 & 55.9 & 4.9 & 44.7 & 75.3 & 38.1 & 31.4 & 273.9 & 264.1 & 106.4 & 81.6 & 67.0 & 50.0 \\
\hline RF Forcast 2050 & 83.4 & 9.9 & 49.7 & 71.0 & 43.1 & 19.4 & 261.9 & 252.1 & 94.4 & 93.6 & 80.7 & 66.0 \\
\hline RH Average & 65 & 55 & 55 & 60 & 47 & 37 & 60 & 60 & 60 & 61 & 57 & 61 \\
\hline RH Average & 65 & 61 & 61 & 61 & 51 & 40 & 60 & 66 & 63 & 61 & 57 & 61 \\
\hline \multirow[t]{3}{*}{ RH Average } & 71 & 67 & 67 & 67 & 57 & 46 & 67 & 76 & 72 & 63 & 61 & 66 \\
\hline & \multicolumn{12}{|c|}{ Favorable months for malaria under future prospect of climate change scenarios } \\
\hline & Jan & Feb & Mar & Apr & May & Jxne & Jul & Aug & Sep & Oct & Nov & Dec \\
\hline \multirow{3}{*}{ Previous term(1986-2016) } & $\mathrm{x}$ & rare & $>18$ & $>18$ & Nil & Nil & Vrare & $>18$ & $>18$ & V.rare & $\mathrm{x}$ & $\mathrm{Nil}$ \\
\hline & $\mathrm{x}$ & rare & $>80$ & $>80$ & $\mathrm{Nil}$ & Nil & Vrare & $>80$ & $>80$ & V.rare & $\mathrm{x}$ & $\mathrm{Nil}$ \\
\hline & $\mathrm{x}$ & rare & $>60 \%$ & $>60 \%$ & $\mathrm{Nil}$ & Nil & V.rare & $>60 \%$ & $>60 \%$ & V.rare & $\mathrm{x}$ & Nil \\
\hline \multirow{3}{*}{ Current mid-term(2020) } & $\mathrm{x}$ & $\mathrm{x}$ & $\mathrm{x}$ & 22.8 & $\mathrm{Nil}$ & Nil & 23.9 & 23.1 & 22.3 & V.rare & $\mathrm{x}$ & Nil \\
\hline & $\mathrm{x}$ & $\mathrm{x}$ & $\mathrm{x}$ & 80.3 & $\mathrm{Nil}$ & Nil & 271.9 & 262.1 & 104.4 & V.rare & $\mathrm{x}$ & $\mathrm{Nil}$ \\
\hline & $\mathrm{x}$ & $\mathrm{x}$ & $\mathrm{x}$ & 60.0 & $\mathrm{Nil}$ & Nil & 60 & 60 & 60 & V.rare & $\mathrm{x}$ & $\mathrm{Nil}$ \\
\hline \multirow{3}{*}{ Near-term $(2030)$} & $\mathrm{x}$ & $\mathrm{x}$ & $\mathrm{x}$ & $\mathrm{x}$ & $\mathrm{Nil}$ & Nil & 23.8 & 23.0 & 22.2 & 20.2 & $\mathrm{x}$ & $\mathrm{Nil}$ \\
\hline & $\mathrm{x}$ & $\mathrm{x}$ & $\mathrm{x}$ & $\mathrm{x}$ & $\mathrm{Nil}$ & Nil & 273.9 & 264.1 & 106.4 & 81.6 & $\mathrm{x}$ & $\mathrm{Nil}$ \\
\hline & $\mathrm{x}$ & $\mathrm{x}$ & $\mathrm{x}$ & $\mathrm{x}$ & $\mathrm{Nil}$ & Nil & 60 & 66 & 63 & 61 & $\mathrm{x}$ & $\mathrm{Nil}$ \\
\hline \multirow{3}{*}{ middle-term $(2050)$} & 21.7 & $\mathrm{x}$ & $\mathrm{x}$ & $\mathrm{x}$ & $\mathrm{Nil}$ & Nil & 25.8 & 25.0 & 24.2 & 22.5 & 19.3 & Nil \\
\hline & 83.4 & $\mathrm{x}$ & $\mathrm{x}$ & $\mathrm{x}$ & $\mathrm{Nil}$ & Nil & 261.9 & 252.1 & 94.4 & 93.6 & 80.7 & $\mathrm{Nil}$ \\
\hline & 71 & $\mathrm{x}$ & $\mathrm{x}$ & $\mathrm{x}$ & $\mathrm{Nil}$ & Nil & 67 & 76 & 60 & 63 & 61 & $\mathrm{Nil}$ \\
\hline
\end{tabular}

When we see the future condition, the transmission of malaria tends to decrease from the Belg season (FMAM) just after the near future term (2020). This is due to the future forecast for precipitation shows a significant decrease over the indicated season. Whereas on July, the occurrence of the disease transforms from very rare to permanent chance of malaria occurrence starting from the period 2020 to 2050. The same is true on October month except that the incidence of malaria is expected to start on period 2030. Further, on the month of November and January the climate condition will be suitable for malaria transmission such that the disease will incur (experience) these months on the last term (2050). These was due sufficient increase of both the temperature and precipitation on these season 
(ONDJ), in the future. This climate effect will allow malaria to exist over elongated duration of months over this season; and there will be a seasonal shift in malaria transmission, in consequence. And, during August and September the transmission continuous in future as it was before. The rest of the months persisted in negative impact for malaria transmission. In general, these opposite effects of temperature and rain fall could, in future, rise a decrease (in number of months from FMAM), an increase (on JJAS) and a seasonal shift in malaria transmission (on ONDJ), in Combolcha woreda.

\section{CONCLUSION AND RECOMMENDATION}

\subsection{Conclusion}

The assessment of the climate showed that the precipitation was suitable for malaria transmission on two seasons (from FMAM to JJAS) in Combolcha woreda, totally. Whereas, in Dekark (below 2,800 $\mathrm{m}$ ) the precipitation favors for malaria incidence on two seasons (May and JJAS) while only on one season (JJAS) in Debark woreda $(>2,800 \mathrm{~m})$. The temperature also was suitable for malaria transmission for several months ranging from February up to October. Whereas, in Debark the temperature was suitable for malaria transmission over lower altitudes $(<2,800 \mathrm{~m})$ on May to September and it was opposing against above this elevation, generally during (1986-2016).

The malaria transmission was common in Combolcha in two seasons before 2001. But, in the period 2002-2008 there was a breakdown/discontinuity in the occurrence of malaria. After, 2008 it reemerges with lower rate of recurrence on FMAM than JJAS. Apart from this, the malaria transmission season was elongated to the first month of the next season (October), in the year 2015 and 2016. Regarding the relation between climate variability and Semi-Decadal differences, the precipitation found to be the leading factor for the decreasing trend/re-emerging event in malaria transmission on FMAM (0.64 correlation value in climate malaria relationship) and on JJAS (0.49). As a result of the above climate factors the malaria transmission showed a decreasing trend during the period (19862016), in Combolcha woreda.

In contrast, in Debark woreda (with elevation below 2,800 m) malaria transmission observed with an increasing trend in consequence of the temperature increase, as a major factor, in general. The temperature was directly related with malaria transmission variability and trend with correlation value 0.53 (JJAS) and 0.37 (FMAM). But, just above the height about 2,800 meter the temperature could not exceed the favorable threshold value $(18 \mathrm{oc})$ for malaria incidence. Finally, in this climate malaria suitability assessment the altitude (2,800 meter) was determined to be the demarcation point-level above which the disease malaria could not existed in Debark woreda for the period (1986-2016). This result agreed to the feed-back mentioned by the health officials of the woreda on the occasion/juncture of NMA's seasonal climate forecasting meeting held in 2016. Moreover, this result was compared with the results obtained by other similar studies [MARA13 malaria model (Source: Ethiopia-Epireport-020520)] which used the same logic and method as done in this research. Thus, this result could screen out the incidence of malaria just at 2,800 $\mathrm{m}$ while it is anticipated at 2,500 $\mathrm{m}$ high based on the projection made by the model for the year 2015 .

In short, we conclude that the change and variability in temperature of the surrounding was more significant in controlling malaria transmission than the rainfall over relative high grounds (Debark). In another way, the change and variability in precipitation takes the first place in controlling malaria transmission over relative lower elevation areas (Combolcha).

Regarding the future prospect of malaria, the overall effects of temperature and rain fall changes could cause a decrease (in number of months from FMAM), an increase (on JJAS) and a seasonal shift in malaria transmission (on ONDJ), in Combolcha woreda. In the same case, the future climate condition particularly the increasing temperature will be suitable for malaria to inhabit over higher and higher elevation in Debark woreda with increased number of months, gradually.

Generally, we conclude that in the face of climate change malaria is pushing upwards the roof of the theoretical limit that nearly $2,000 \mathrm{~m}$ was the elevation beyond which malaria was believed unlikely to exist.

\subsection{Recommendation}

For relatively higher elevated places, over shorter range of spatial coverage and with complex topography (like in Debark woreda) the gridded data was able to show the actual conditions with high spatial resolution over a given small locality. Therefore, it is recommended to use this data option when and where there is a lack of ability to display the actual facts on the ground due to using the station data for large area coverage. 
The procedure developed in a new way in this study and tested for the first time to display the climate malaria suitability information in a tabular form is appropriate for point location than on a map which is better form for the whole of the country. Therefore, this technique is recommended also to be used as supplementary for both small area coverage as well as for the country wide.

Apart from this, the relationship between climate and health (particularly like malaria) can be regarded and used as a climate monitoring tool. Climate monitoring in a sense is that if the nature of the malaria transmission is changed over a certain place one can think that there is a sign of climate change over that place.

\section{REFERENCES}

[1] Arab et al. (2014), Modeling the effects of weather and climate on malaria distributions in West Africa, USA: BioMed Central malaria Journal, 9pp.

[2] A. Be'guin et al. (July, 2011), The opposing effects of climate change and socio-economic development on the global distribution of malaria, article in Global Environmental Change 1209-1214, Germany: ELSEVIER, 6pp.

[3] A.J. McMichael et al. (2003), Climate change and human health: Risks and Responses, GENEVA: WORLD HEALTH ORGANIZATION, 333pp.

[4] Author's Guide, (2014), 'An Overview of the Impact of Climate Change on Public Health with Regard to Malaria's Cause, Treatment and Resurgence' from the book of CLIMATE CLIMATE CHANGE AND PUBLIC HEALTH: Malaria, 19pp.

[5] Author's Guide, (May, 2012), Malaria interpolation procedure and methodology for Ethiopia and Africa, Niger: document reported by ACMAD, $15 \mathrm{pp}$.

[6] A. Haines et al. (March 20, 2006), Climate change and human health: Impacts, vulnerability and public health, London, UK: Elsevier Ltd, 12 pp:

[7] B. Lyon et al. (15 June, 2017), Temperature suitability for malaria climbing the Ethiopian Highlands, Newyork, USA: Environmental Research Letters, 8pp.

[8] C. McSweeney et al, (2006), Climate change country profiles of Ethiopia, School of Geography and Environment University of Oxford: UK, Tyndall center of Climate change, 27pp

[9] C. Caminade et al. (2012), The impact of climate change on malaria distribution in Africa: a multi-model approach, QWeCI Third Annual Meeting, Nairobi: WeCI and University of Liverpool, 32pp.

[10] F. Bosello et al. (13 October 2005), Economy-wide estimates of the implications of climate change: Human health, Italy: Elsevier Ltd, 13pp

[11] F. C. Tanser et al. (2003), Potential effect of climate change on malaria transmission in Africa, South Africa: article presented by THE LANCET $\bullet$ Vol $362,7 \mathrm{pp}$.

[12] FDRE MoWIE, (Feb., 2017), Climate information for the Health sector, Health Bulletin in Applied meteorological service case Team, Volume XI, No. 08, Addis Ababa: NMA, 7pp.

[13] G. Kopec et al. (11 May, 2006), Web-based climate information resources for malaria control in Africa, New York, USA: BioMed central Ltd., 9pp.

[14] Global Malaria Program, (Aug., 2017), WHO Malaria Terminology, Geneva, Switzerland: World Health Organization and Global Malaria Programme, $38 \mathrm{pp}$ :

[15] H. F. DAIZ and R. S. BRADLEY (1997), Temperature variations during the last century at high elevation sites: Netherlands, Climate change Journal: Kluwer Academic Publishers, 27pp

[16] ICPAC (March, 2016), Projected changes in rainfall and temperature over Greater Horn of Africa (GHA) in different scenarios: Nairobi, Kenya, ICPAC, 18pp

[17] IPCC (2012 \& 2015), A report on climate change impacts, Fact sheet no. 2, and no. 5, International panel of climate change, UNDP: Switzerland, Jeneva, 16pp

[18] I. Rangwala \& J. R. Miller (January, 2012), Climate change in mountains: a review of elevation-dependent warming and its possible causes: USA, Climatic Change DOI 10.1007/s10584-012-0419-3, Springer Science+Business Media B.V. 2012, 21pp

[19] I. R. Orimoloye et al. (2018), Assessing changes in climate variability and simulation of Temperature and Relative humidity, South Africa: Research journal of Env. Science, Cross mark, 14pp

[20] J. A. Patz et al. (2003), 'Climate change and infectious diseases', chapter six, in the book of Climate Change and Human Health, Geneva: World Health Organization,30 pp.

[21] K. F. Ahmed et al. (November, 2012), Statistical downscaling and bias correction of climate model outputs for climate change impact assessment in the U.S. northeast, USA, Global and Planetary Change 100 (2013) 320-332, ELSEVIER, 320PP

[22] L.K. Amekudzi et al. (Dec., 2014), The impact of climate change on malaria in coastal Ghana, Ghana: ResearchGate, Technical Report. December 2014, 5pp. 
[23] M. Andreas, (October, 2012), Abilities and limitations in the use of Regional Climate Models, University of Oslo No. 1236 ISSN 1501-7710, Akademika, 104pp.

[24] Media Dordrecht, 11pp. Medical press, (June, 2017), Temperature changes make it easier for malaria to climb the Ethiopian highlands: Medical Press, 2pp.

[25] M. Franchini et al. (2014), 'Impact on human health of climate changes' in the document of European Journal of Internal Medicine 26 (2015) 1-5, Europe, ELSEVIER B.V., 5pp.

[26] Ministry of Forests, Lands, and Natural Resource Operations, (13 December, 2013), Climate Change Assessment Guide, Province of British Columbia: British Columbia, 18 pp:

[27] M. Lunde1 et al. (2013), How malaria models relate temperature to malaria transmission, Norway: BioMed Central, 10pp.

[28] M. Tesi, (Aug., 2011), Global Warming and Health: The Issue of Malaria in Eastern Africa's Highlands, Canada: Africa Initiative and The Centre for International Governance Innovation, 20pp

[29] M. Van Lieshouta et al. (2004), Climate change and malaria: analysis of the SRES climate and socioeconomic scenarios, UK: Elsevier Science Ltd., 13pp

[30] Pendergrass, Angeline \& National Center for Atmospheric Research (Eds). Updated (02 Jul 2016), "The Climate Data Guide: GPCP (Monthly): G. Precipitation Climatology Project."

[31] P. L. Kinney, (2008), Climate Change, Air Quality, and Human Health, USA: American Journal of Preventive Medicine, Volume 35, Number 5 : 9pp.

[32] P. L. Kinney et al. (2007), Approaches for estimating effects of climate change on heat-related deaths: challenges and opportunities, USA, ELSEVIER Ltd., 10pp

[33] P. Martens et al. (2 June, 1999), Climate change and future populations at risk of malaria, UK: Elsevier Science Ltd., 19pp

[34] S. H Sherwood et al (May, 2010), Relative humidity changes in a warmer climate, J. Geophys. Res., 115, D09104, doi:10.1029/2009JD012585. 11pp

[35] S. Kovats \& R. Akhtar, (2008), 'Climate, climate change and human health in Asian cities', in the report of International Institute for Environment and Development (IIED), 165 Vol 20(1): 165-175.

[36] T. Ikeda et al. (29 May, 2017), Seasonally lagged effects of climatic factors on malaria incidence in South Africa, South Africa: Scientific Reports-6, 9pp.

[37] T. Ngarakana-Gwasira et al. (23 February, 2016), Assessing the Role of Climate Change in Malaria Transmission in Africa, Zimbabwe: Hindawi Publishing Corporation,

[38] USAID, (Sept., 2015), Climate Change Information Fact Sheet ETHIOPIA: article from FEWSNET, Ethiopia, 3pp

[39] WMO \& WHO. (Sept., 2015), Climate Change and Malaria, Factsheet \#2: Climate information for protecting human health (2009), Geneva: WMO \& WHO, 3pp.

[40] Z. T. Segele et al., (April, 2008), Evaluation and adaptation of a regional climate model for the Horn of Africa: rainfall climatology and interannual variability: USA, International Journal of Climatology: RMetS, 19pp.

[41] The Fifth Assessment Report of the IPCC, (http://www.ipcc.ch/report/ar5/wg1/)

[42] Definition of Climate Change, (http://www.wired.co.uk/article/what-is-climate-change-definition-causeseffects)

[43] http://study.com/acadamy/lesson/global--climate-types-advantages-disadvantages.html

[44] http://www.ciesin.columbia.edu/

[45] www.climate.be/textbook/chapters.node.html

[46] http://phy.org/news/2008-04-good-climate.html\#jcp

[47] Cicsnc.org, ncsu.edu and ncei.noaa.com

[48] http://earthobservatory.nasa.gov/Features/watervapor/

Citation: Abrhame Weldeyohannes Gilgel (Msc), et.al, " Assessment and Projection of Climate Change Impacts on Malaria Distribution in Ethiopia: Case of Combolcha and Debark Districts ", International Journal of Research in Environmental Science (IJRES), vol. 5, no. 4, pp. 20-42, 2019. Available: DOI: http://dx.doi.org/10.20431/2454-9444.0504003

Copyright: (C) 2019 Authors. This is an open-access article distributed under the terms of the Creative Commons Attribution License, which permits unrestricted use, distribution, and reproduction in any medium, provided the original author and source are credited. 